\title{
The High-Density Hydrogen Carrier Intercalation in Graphane-Like Nanostructures, Relevance to its On-Board Storage in Fuel-Cell-Powered Vehicles
}

\author{
Yury S. Nechaev*
}

Kurdjumov Institute of Metals Science and Physics, within Bardin Institute for Ferrous Metallurgy, Vtoraya Baumanskaya St., 9/23, Moscow 105005, Russia

\begin{abstract}
Theoretical (thermodynamic) and experimental backgrounds are considered for developing a much simpler, more technological and effective method (in comparison with the known megabar compression dynamic and static methods) of producing a high-density solid molecular ("reversible") hydrogen carrier by means of hydrogen intercalation (at the cost of the hydrogen association energy) in carbonaceous nanomaterials (between graphane-like layers) at relevant temperatures and pressures. As is shown, one of the processes of chemisorption of hydrogen in carbonaceous nanomaterials may be related to formation of graphane-like (carbohydride-like) complexes and/or multilayer graphane-like nanostructures. In this connection, some aspects of the graphene/graphane problem are considered, as well. By using gravimetric and electron microscopy data, the density values $\left(\rho_{\mathrm{H}}=0.7 \pm 0.2 \mathrm{~g}\left(\mathrm{H}_{2}\right) / \mathrm{cm}^{3}\left(\mathrm{H}_{2}\right)\right.$, and $\rho_{\mathrm{H}}^{*}=0.28 \pm 0.08 \mathrm{~g}\left(\mathrm{H}_{2}\right) / \mathrm{cm}^{3}\left(\mathrm{system}^{3}\right)$ - the "volumetric" capacity) of the intercalated solid molecular ("reversible") hydrogen (of a high purity) in graphane-like nanofibers ( $\geq 15$ mass $\% \mathrm{H}_{2}$ - the "gravimetric" capacity) have been defined. It is a much more acceptable, safe and efficient technology, in comparison with the current technologies of composite vessels with high hydrogen pressure (about 80 $\mathrm{MPa}$ ) and the current space cryogenic technologies of hydrogen on-board storage in fuel-cell-powered vehicles. It exceeds and/or corresponds to the known U.S. DOE requirements-targets for 2015, with respect to the hydrogen capacities, safety, reversibility and puirity.
\end{abstract}

Keywords: Carbon-based nanomaterials, High-density solid molecular reversible hydrogen carrier, Graphane-like (carbohydride) multilayer nanostructures, Graphene/graphane problem, Hydrogen on-board efficient and safety storage.

\section{INTRODUCTION}

As is noted in [1], the main problem of using hydrogen as a fuel is the gaseous nature of hydrogen molecules, requiring their compression in heavy and somewhat unsafe pressurized gas cylinders to enable transport and storage of the fuel. The energy content of hydrogen is the highest of any fuel that exists (except nuclear fuel) for vehicles, rockets and other applications relative to the mass of hydrogen alone $[1,2]$. Thus, as is emphasized in [1], it becomes necessary to find forms of hydrogen that can be stored and transported without much overhead, while still retaining the high energy content of hydrogen gas. In a series of articles $([1,3,4]$ and some others), a novel method (based on theoretical predictions [5]) is described for producing atomic hydrogen material of high density of $0.5-0.7 \mathrm{~g} / \mathrm{cm}^{3}$, but only in microscopic amounts. In this method, hydrogen gas is absorbed in a K-promoted iron oxide catalyst (a hydrogen-abstract catalyst) and desorbs as clusters containing $\mathrm{H}$ atoms at low pressure and temperature of $<900$. K. The results are compared to the dynamic (shock-wave) or static (in the diamond-anvil cell) megabar compression experiments ([6-9] and others). Hence, it is concluded $[1,3,4]$ that the resulting atomic hydrogen material is a metallic quantum liquid.

*Address correspondence to this author at the Kurdjumov Institute of Metals Science and Physics, within Bardin Institute for Ferrous Metallurgy, Vtoraya Baumanskaya St., 9/23, Moscow 105005, Russia; Tel: +(7495)4910262; Fax: +(7-495)7779350; E-mail: yuri1939@inbox.ru
In the following sections, the theoretical (thermodynamic) and experimental backgrounds are described (in the light of results [10-12]) to develop a much more efficient and safety method (compared to [1-9]) of producing a highdensity $\left(\sim 0.70 \mathrm{~g}\left(\mathrm{H}_{2}\right) / \mathrm{cm}^{3}\left(\mathrm{H}_{2}\right)\right)$ solid molecular ("reversible") hydrogen carrier of a high purity and safety (with the "volumetric" capacity $\sim 0.3 \mathrm{~g}\left(\mathrm{H}_{2}\right) / \mathrm{cm}^{3}$ (system) and the "gravimetric" capasity $\geq 17$ wt $\% \mathrm{H}_{2}$ ).

It is shown that such unique hydrogen can be intercalated at relevant temperatures and pressures in some carbonaceous multilayer nanomaterials between graphane-like (within terminology $[13,14]$ ) nanoregions (at the expense of the association energy of hydrogen atoms to molecules).

In this connection, some aspects of the graphene/graphane problem [13, 14], relevance to multilayer graphene-like structures, are considered in the folling sections, as well.

The present hydrogen storage nanotechnology is much more acceptable, safety and efficient, in comparison with the current technologies of composite vessels with high hydrogen pressure (about $80 \mathrm{MPa}$ ) and the current space cryogenic technologies of hydrogen on-board storage in fuel-cellpowered vehicles. And the present nanotechnology exceeds (in some points) and/or corresponds to the known U.S. DOE requirements-targets for 2015 (with respect to the hydrogen capacities, safety, reversibility and puirity). 
It's relevant to note that the U.S. Department of Energy (DOE) has established different targets and requirements for on-board hydrogen storage systems in ecologically clean fuel-cell-powered vehicles (www.eere.energy.gov/hydrogenandfuelcells). Their strategic objectives for the year 2015 include a minimum "gravimetric" capacity (weight of stored reversible $\mathrm{H}_{2}$ /system weight) of 9.0 wt $\%$, and a "volumetric" capacity (density) of $0.081 \mathrm{~g}$ (reversible $\left.\mathrm{H}_{2}\right) / \mathrm{cm}^{3}$ (system).

\section{THE INTERCALATION OF HIGH-DENSITY HY- DROGEN CARRIER INTO NEAR-SURFACE GRA- PHENE LAYERS}

A real possibility of hydrogen intercalation into (between) near-surface graphene layers of highly oriented pyrolytic graphite (HOPG) has been shown in some experimental studies [15-20]. It has been analyzed in [10-12] which also takes into account results [21-42].

The present study considers some new and very important aspects of this problem. Hence, some self-plagiarism of [10-12] in this article is necessary.

Atomic hydrogen accumulation in HOPG samples and etching their surface on hydrogen thermal desorption (TD) [15] have been studied using a scanning tunneling microscope (STM) and atomic force microscope (AFM).
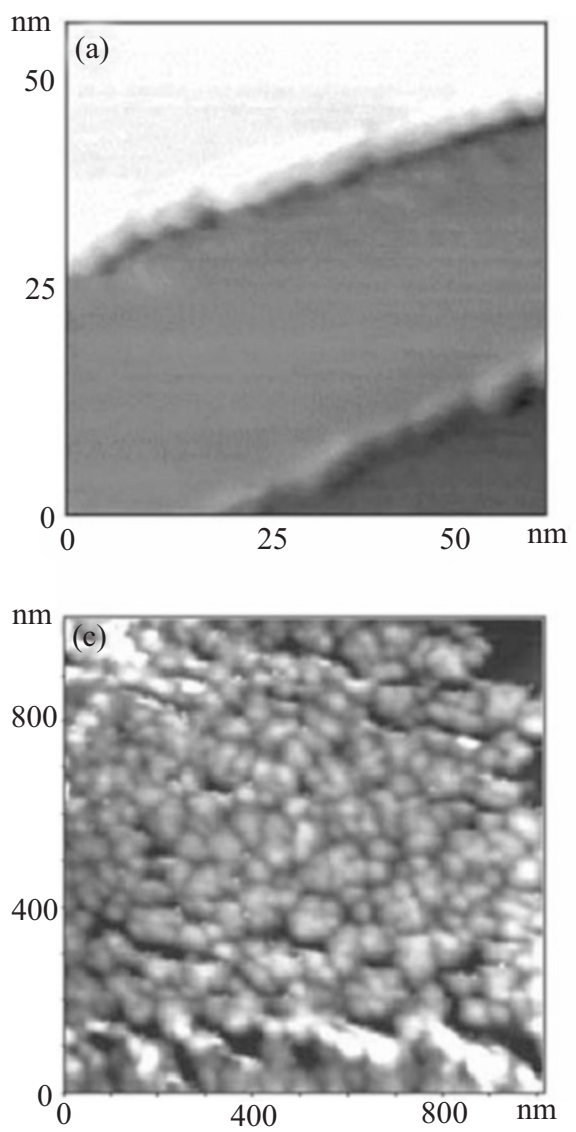

STM investigations [15] revealed that the surface morphology of untreated reference HOPG samples was found to be atomically flat (Fig. 1a), with a typical periodic structure of graphite (Fig. 1b). Exposure (treatment) of the reference HOPG samples (30-125 min at external atomic hydrogen pressure $P_{\mathrm{H}} \approx 1 \mathrm{~Pa}$ and near-room temperature) to different atomic hydrogen doses (D) has drastically changed the initially flat HOPG surface into a rough surface, covered with bumps-blisters (Fig. 1c), with an average height, as shown in Fig. 1d, of about $4 \mathrm{~nm}$.

Desorption of hydrogen has been found on TD heating of the HOPG samples under mass spectrometer control (Fig. 2a). As is shown in Fig. 2a, with the increase of the total hydrogen doses (D) to which HOPG samples have been exposed the desorbed hydrogen amounts $(\mathrm{Q})$ increase and the percentage of $\mathrm{D}$ retained in samples $(\mathrm{Q})$ decreases towards a saturation stage. After TD, no bumps were visible on the HOPG surface, the graphite surface was atomically flat, and covered with some etch-pits of nearly circular shapes, one or two layers thick (Fig. 2b). This implies that after release of the captured hydrogen gas, the bumps-blisters become empty of hydrogen and the HOPG surface restores back a flat surface morphology under action of Van der Waals forces [15].

According to [15], bumps found on the HOPG surface after atomic hydrogen exposure are simply monolayer graphite (graphene) blisters, containing hydrogen gas in molecular
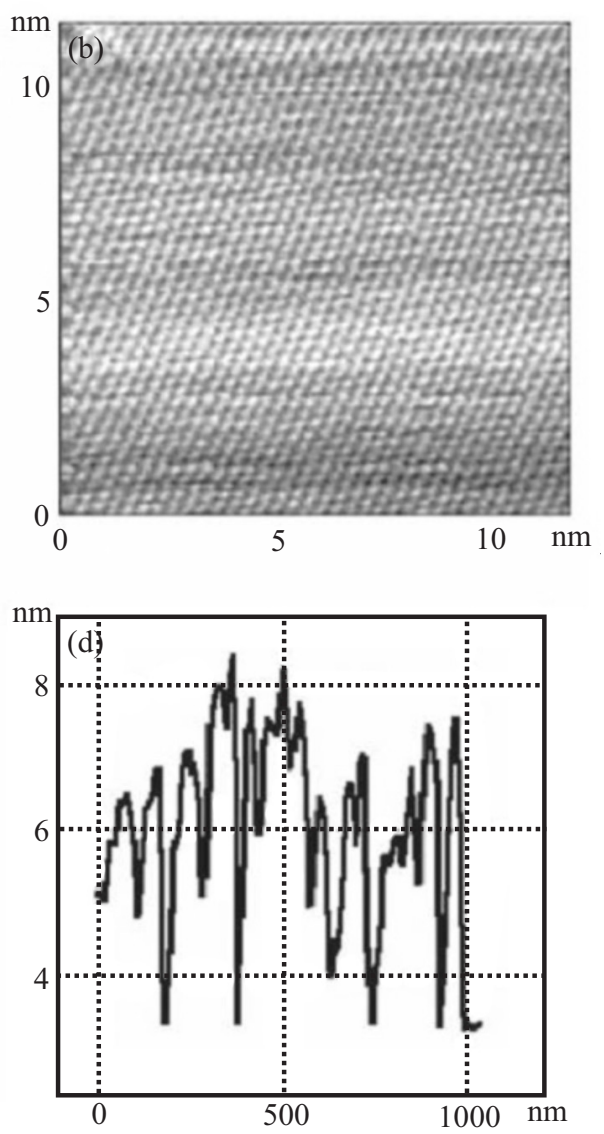

Fig. (1). STM images of the untreated HOPG sample (under ambient conditions) taken from areas of (a) $60.8 \times 60.8 \mathrm{~nm}$ and (b) $10.9 \times 10.9$ $\mathrm{nm}$ (high resolution image of the square in image (a)). (c). AFM image (area of 1x1 nm) of the HOPG sample subjected to atomic hydrogen dose (D) of $1.8 \cdot 10^{16} \mathrm{H}^{0} / \mathrm{cm}^{2}$. (d) Surface height profile obtained from the AFM image reported in (c). The STM tunnel $\mathrm{V}_{\text {bias }}$ and current are 50-100 $\mathrm{mV}$ and 1-1.5 mA, respectively [15] (with the permition). 


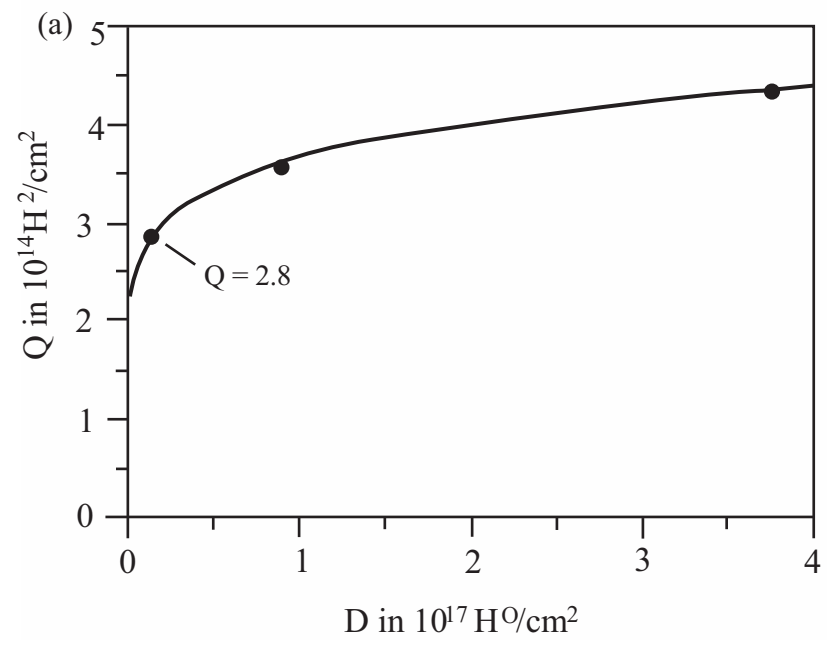

(b)

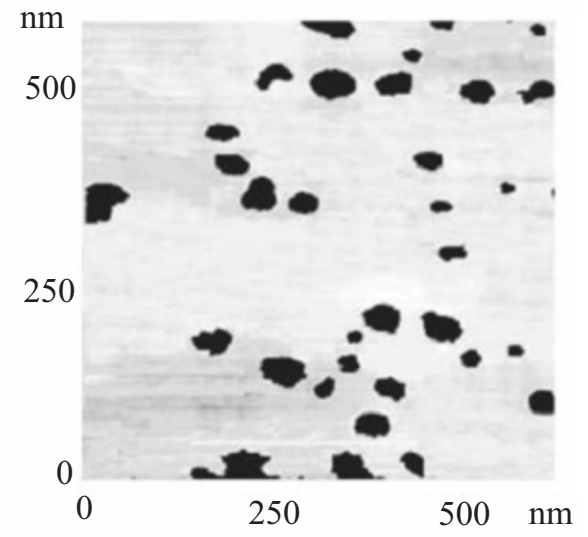

Fig. (2). (a) Hydrogen storage efficiency of HOPG samples, desorbed molecular hydrogen (Q) versus dose (D) of atomic hydrogen exposure. (b) STM image for $600 \times 600 \mathrm{~nm}$ area of the HOPG sample subjected to atomic hydrogen dose of $1.8 \cdot 10^{16} \mathrm{H}^{0} / \mathrm{cm}^{2}$, followed by hydrogen thermal desorption (TD) [15] (with the permition).

form. As is suggested in [15], atomic hydrogen intercalates between layers in the graphite net through holes in graphene hexagons (due to the small diameter of atomic hydrogen compared to the hole size) and is then converted to a $\mathrm{H}_{2}$ gas form (obviously, a high purity hydrogen) which is captured inside the graphene blisters (due to the relatively large kinetic diameter of hydrogen molecules).

It was found in [15] that the average blister has radius 25 $\mathrm{nm}$ and height $4 \mathrm{~nm}$. If the blister is considered to be a semiellipse, blister area $\left(S_{\mathrm{b}} \approx 2.0 \cdot 10^{-11} \mathrm{~cm}^{2}\right)$ and its volume $\left(V_{\mathrm{b}} \approx\right.$ $\left.8.4 \cdot 10^{-19} \mathrm{~cm}^{3}\right)$ were found [15]. The amount of retained hydrogen in this sample was $Q \approx 2.8 \cdot 10^{14} \mathrm{H}_{2} / \mathrm{cm}^{2}$ and the number of hydrogen molecules captured inside the blister was $(Q$ $\left.S_{\mathrm{b}}\right) \approx 5.5 \cdot 10^{3}$ [15]. Thus (within the ideal gas approximation [21]) the internal pressure of molecular hydrogen in a single blister at room temperature $(T)$ is $P_{\mathrm{H} 2} \approx k\left(Q S_{\mathrm{b}}\right) T / V_{\mathrm{b}} \approx$ $2.5 \cdot 10^{7} \mathrm{~Pa}, k$ - being the Boltzman constant; the estimated accuracy is not higher than the order of magnitude. During TD heating, for instance, at $1,000 \mathrm{~K}$ the pressure can reach a level of $P_{\mathrm{H} 2} \approx 8.5 \cdot 10^{7} \mathrm{~Pa}$, which can be enough for some blisters to get punctured (or tensile ruptured), possibly due to some defects in their roofs (walls).

In [15], the pressure levels are compared with known experimental values of tensile and compressive strengths for graphite $-10^{7} \mathrm{~Pa}$ and $3 \cdot 10^{7} \mathrm{~Pa}$, respectively. But it seems more reasonable to take into account the recent data on elasticity, strength and toughness of carbon nanorods and nanotubes, for instance, [22, 23], data [24] on stress-strain state of multiwall carbon nanotubes under internal pressure, data [25] on carbon onions as nanoscopic pressure cells for diamond formation, and data [26] on the elastic properties and intrinsic strength of monolayer graphene. As is noted in [26], their experiments establish graphene (a defect-free monolayer sheet) as the strongest material ever measured. In studies [22-26] much higher values (by several orders of magnitude, in comparison with graphite) of elasticity modulus, modulus of elongation and tensile strength are declared. Hence, it follows: (i) that the blister formation in HOPG [15] at room temperatures can occur under elastic deformation conditions, and (ii) that a counteraction blister pressure (of the fugacity order) should be taken into account (within both the mechanical and thermodynamic considerations).

By using the stress obtained above (pressure in a blister) as $\sim 10^{8} \mathrm{~Pa}$, and finding from data [15] the local elastic deformation degree of a blister roof as $\sim 0.1$, one can estimate (within Hooke's law) the modulus of elasticity of the defect surface graphene layer in HOPG as $\sim 10^{9} \mathrm{~Pa}$. This value is about two orders higher than the known quantity for graphite, but about two orders lower than the quantity for more perfect graphene in carbon nanotubes, nanorods and monolayer graphene (a defect-free sheet) [22-26]. The defect structure of the surface graphene layer in HOPG can be caused by some known fragmentation of HOPG structure, probably, providing the ready critical nuclei for the blisters.

It is also consistent with the thermodynamic estimation of the equilibrium hydrogen fugacity $\left(f_{\mathrm{H} 2}\right)$ in the blisters in [15] which can be made by using the law of mass action for the reaction of $2 \mathrm{H}_{\text {(gas) }} \leftrightarrows \mathrm{H}_{2 \text { (gas_in_blisters), }}$, as follows:

$\left(f_{\mathrm{H} 2} / P^{0}\right) \approx\left(P_{\mathrm{H}} / P^{0}\right)^{2} \exp \left\{\left[\Delta H_{\mathrm{dis}}-T \Delta S_{\mathrm{dis}}-f_{\mathrm{H} 2}(\Delta V / n)\right] / R T\right\}$,

where $P_{\mathrm{H}} \approx 1 \mathrm{~Pa}$ is the atomic hydrogen pressure in the atomizer in [15], $P^{0}=1 \mathrm{~Pa}$ is the standard pressure, $\Delta H_{\mathrm{dis}}=$ $448 \mathrm{~kJ} / \mathrm{mol}\left(\mathrm{H}_{2}\right)$ is the known experimental value of the dissociation energy (enthalpy) of one mole of gaseous hydrogen (at room temperatures), $\Delta S_{\mathrm{dis}}=98.5 \mathrm{~J} / \mathrm{K} \cdot \mathrm{mol}$ (from the standard thermodynamic quantities) is the dissociation entropy, $\Delta V \approx V_{\mathrm{b}}, n \approx\left(Q S_{\mathrm{b}}\right) / N_{\mathrm{A}}, N_{\mathrm{A}}$ is the Avogadro number, $R$ is the gas constant, $T \approx 300 \mathrm{~K}$ in [15]; hence, $f_{\mathrm{H} 2} \approx 10^{9} \mathrm{~Pa}$. Such a value can be related to the saturation stage in [15] for $Q \geq$ $4 \cdot 10^{14} \mathrm{H}_{2} / \mathrm{cm}^{2}$.

The hydrogen volumetric (mass) density in the blisters in [15] can be estimated as $\rho \approx\left\{\left(Q M_{\mathrm{H} 2} S_{\mathrm{b}}\right) / V_{\mathrm{b}}\right\} \approx 0.045$ $\mathrm{g}\left(\mathrm{H}_{2}\right) / \mathrm{cm}^{3}\left(\mathrm{H}_{2}\right)$, where $M_{\mathrm{H} 2}$ is the hydrogen molecule mass; this is close (within the errors) to the liquid hydrogen mass density $\left(0.071 \mathrm{~g} / \mathrm{cm}^{3}\right.$ at $21.2 \mathrm{~K}$ and $\left.0.1 \mathrm{MPa}\right)$.

By using Eq. 1, one can show that the hydrogen volumetric (mass) density in the graphene blisters in [15] could reach a value of $\sim 0.7 \mathrm{~g}\left(\mathrm{H}_{2}\right) / \mathrm{cm}^{3}\left(\mathrm{H}_{2}\right)$ at $P_{\mathrm{H}} \approx 100 \mathrm{~Pa}$ corresponding to $f_{\mathrm{H} 2} \approx 10^{11} \mathrm{~Pa}$, i.e. a "megabar" hydrogen pressure. This 
"open" question is discussed further, relevance to multilayer graphene structures, in the next sections.

By using the experimental and estimated results considered above, one can conclude that there is some threedimensional clustering of hydrogen molecules in the graphite near-surface regions (between the two graphene layers), i.e., there is formation and growth of liquid-like threedimensional nanoclusters under the conditions given in [15].

It is consequently relevant to point, for instance, to results [27] of molecular dynamics simulations of hydrogen molecule liquefaction on exterior (deformed) surfaces of single-walled carbon nanotube (SWNT) bundles (at $80 \mathrm{~K}$ and $10 \mathrm{MPa}$ ). Those studies were carried out in relation to experimental findings on some hydrogen phase transitions in SWNT bundles [28].

It is also relevant to compare data [15] with related results [20] of studying the graphite surface modifications induced by interaction between hydrogen atoms (respectively deuterium) and perfectly crystalline HOPG surfaces. The surface properties were probed [20] with high-resolution electron-energy-loss spectroscopy (HREELS) revealing the formation of $\mathrm{C}-\mathrm{H}$ units with different vibration energies. Comparison of the results (in [20]) with the density functional theory (DFT) calculations [29] established models of the hydrogen adsorption processes at the graphite surface. It was shown in [20] that vibration at $295 \mathrm{meV}$ was due to a single $\mathrm{H}$ atom bonding to graphite $(\mathrm{C}-\mathrm{H})$, while vibrations at $331 \mathrm{meV}$ and $345 \mathrm{meV}$ (and higher energy losses) were respectively related to formation of dimer and quartet, or more generally, a higher number of clustering atoms (i.e., hydrogen cluster formation). Subsequently, studies were performed in [20] by using scanning tunneling microscopy (STM). From the electron viewpoint in [20], as hydrogen locally disturbed the electron density near the Fermi level, charge density confinement was observed between the hydrogen clusters, particularly when using low tip-sample bias voltage.

It is also necessary to take into account the experimental data [16-19] on hydrogen thermal desorption (TD) from highly oriented pyrolytic graphite (HOPG) exposed to atomic hydrogen (as in [15]) at near-room temperatures, and their constructive (thermodynamic) analysis [10-12]. As was shown in [16-19], such treatment resulted in emergence of surface nano-hillocks (nano-blisters) with heights of 3-5 nm and diameters of 40-75 nm, most of which disappeared after hydrogen thermal desorption that occurred as a first-order reaction [17, 18]. The TD measurements in [16-19] (at a heating rate of $v=25 \mathrm{~K} / \mathrm{s}$ ) revealed two TD peaks (processes): a peak $\alpha$ centered at $T_{\alpha} \approx 1123 \mathrm{~K}\left(\Delta T_{\alpha} \approx 180 \mathrm{~K}-\right.$ its width at half of its height, $S_{\alpha} / S_{\Sigma} \approx 0.45$ - its fraction of the total spectrum area, $Q_{\alpha} \approx 230 \mathrm{~kJ} / \mathrm{mol}$ - activation energy of the process) and TD peak $\beta$ centered at $T_{\beta} \approx 1523 \mathrm{~K}\left(\Delta T_{\beta} \approx\right.$ $250 \mathrm{~K}, S_{\beta} / S_{\Sigma} \approx 0.55, Q_{\beta} \approx 385 \mathrm{~kJ} / \mathrm{mol}$ ).

Using analyses results [10-12] and the aforementioned results, one can attribute the TD process (peak) $\alpha$ to process III of dissociative chemisorption of hydrogen between graphene layers (Table 1 in [12], model " $F_{1}$ " in Fig. 4). The rate-controlling stage of the process (peak) $\alpha$ can be attributed to diffusion of hydrogen atoms (between the two surface graphene layers from the nearest graphene blisters to a "punctured" one (accompanied by hydrogen reversible trapping, i.e., $\mathrm{C}-\mathrm{H}$ bonding at chemisorption centers in the graphene layers (model " $F_{1}$ " in Fig. 4). The diffusion characteristics of the processes $\alpha$ (or III) are as follows: diffusion activation energy $Q_{\alpha} \approx Q_{\mathrm{III}} \approx 250 \mathrm{~kJ} / \mathrm{mol}(\mathrm{H})$, pre-exponential factor of the diffusion coefficient $D_{0 \alpha} \approx D_{0 \text { III }} \approx 3 \cdot 10^{-3} \mathrm{~cm}^{2} / \mathrm{s}$ (Table 1 in [12]), and diffusion coefficient $D_{\alpha} \approx D_{\text {III }} \approx 7 \cdot 10^{-15}$ $\mathrm{cm}^{2} / \mathrm{s}$. Hence, the diffusion length $\left(D_{\alpha} \Delta T_{\alpha} / v\right)^{1 / 2}$ is on order of 1-10 nm, i.e., as the separation between the walls of the neighboring blisters (in [15]). It can be related to study results given in [20] on the vibration contribution at $295 \mathrm{meV}$ due to a single $\mathrm{H}$ atom bonding to graphite $(\mathrm{C}-\mathrm{H})$.

In the same way, one can attribute the TD process (peak) $\beta$ to process IV of dissociative chemisorption of hydrogen between graphene layers with some defects, for instance, as dislocation loops (Table 1 in [12], models " $C_{1}$ " and/or " $D_{1}$ " in Fig. 4). The rate-controlling stage of the process (peak) $\beta$ can be attributed to diffusion of hydrogen atoms (between the two surface graphene layers) from the available graphene blisters to a "punctured" one (with concomitant hydrogen reversible trapping, i.e., $\mathrm{C}-\mathrm{H}$ bonding at chemisorption centers in the defect regions of the graphene layers (models " $\mathrm{C}_{1}$ " and/or " $\mathrm{D}_{1}$ " in Fig. 4). The diffusion characteristics are $Q_{\beta} \approx$ $Q_{\mathrm{IV}} \approx 365 \mathrm{~kJ} / \mathrm{mol}(\mathrm{H}), D_{0 \beta} \approx D_{0 \mathrm{IV}} \approx 6 \cdot 10^{2} \mathrm{~cm}^{2} / \mathrm{s}$ (Table 1 in [12]), and $D_{\beta} \approx D_{\mathrm{IV}} \approx 2 \cdot 10^{-10} \mathrm{~cm}^{2} / \mathrm{s}$; the diffusion length $\left(D_{\beta}\right.$ $\left.\Delta T_{\beta} / v\right)^{1 / 2}$ is on order of $10^{2} \mathrm{~nm}$, i.e., as the separation between the neighboring etch-pits (in [15]). The defects of the dislocation loop type can be formed (created) during (and/or due to) shrinking and/or disappearing of a number of blisters.

Publication [15] considered that the etching mechanism (i.e., creating etch-pits on the surface due to release of some hydrogen (a small amount) together with carbon atoms (obviously, as hydrocarbon complexes) from the hole edges (in punctured graphene blisters), resulting in bigger sizes of the holes, can be attributed to process II of dissociativeassociative chemisorption of hydrogen molecules (Table $\mathbf{1}$ in [12], model "H" in Fig. 4). As has been shown in [12], only process II (from those considered I-IV in Table $\mathbf{1}$ in [12]) is characterized by a concomitant (initiated by the process) occurrence of a fairly small amount of hydrocarbons $\left(\mathrm{CH}_{4}\right.$ and others) in the thermal desorption (TD) spectra. The explanation for this phenomenon is that the energy $\left(-\Delta H_{(12) \mathrm{II}} \approx\right.$ $560 \mathrm{~kJ} / \mathrm{mol}\left(\mathrm{H}_{2}\right)$, Table 1 in [12]) of desorption (detachment) of two hydrogen atoms from the carbon atom of the sorption center (model " $\mathrm{H}$ " in Fig. 4) is higher than the energy $\left(-\Delta H_{\mathrm{C}}\right.$ $\mathrm{C} \approx 485 \mathrm{~kJ} / \mathrm{mol}$ ) of detachment of this carbon atom from its two nearest carbon neighbors. Process II may be related to results in [20] on the vibration contribution at $331 \mathrm{meV}$ due to a dimer of hydrogen atoms bonding to graphite.

And as it can be shown [10,41,42], by comparing results $[11,12]$ and $[13,14]$, there are serious reasons to suggest that the TD peak $\alpha$ in $[17,18]$, corresponding to process III of dissociative chemisorption of hydrogen between graphene layers (Table 1 in [12], model " $F_{1}$ " in Fig. 3) may be related to the graphane-like situation in the material.

As is estimated in [13], the standard energy (enthalpy) of formation of graphane from graphite and molecular gaseous hydrogen is $\Delta H_{\mathrm{f} \text { (theor.) }}^{0}=-0.15 \pm 0.05 \mathrm{eV} /$ atom $(\mathrm{C})$. Hence, by using the known experimental value of the dissociation energy of molecular gaseous hydrogen, one can define the bonding energy of atomic hydrogen with graphane as $\Delta H_{\mathrm{C}-}$ 


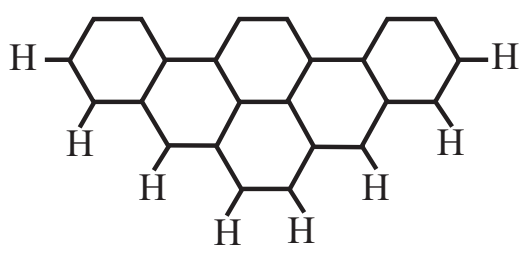

A

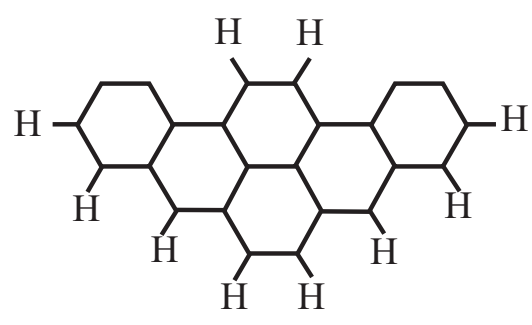

C

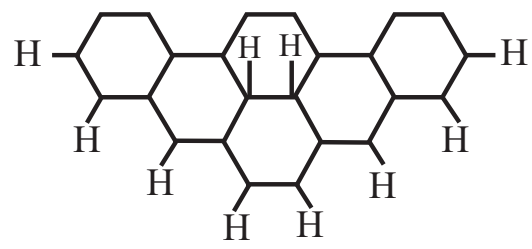

E

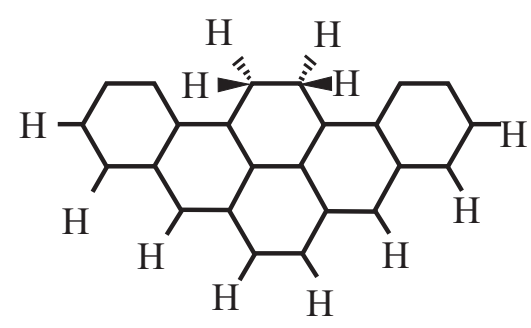

G
$\mathrm{H}$

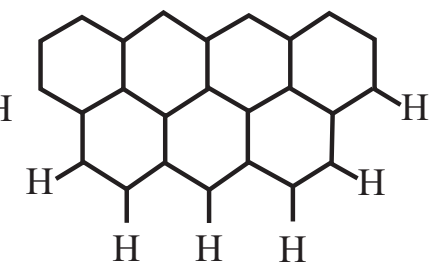

B

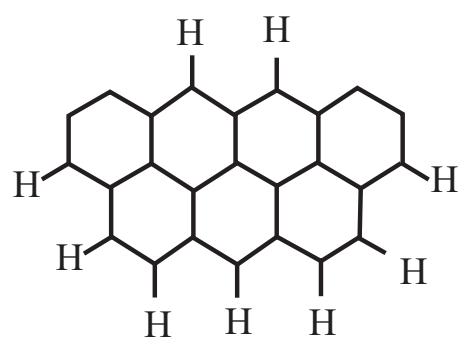

D

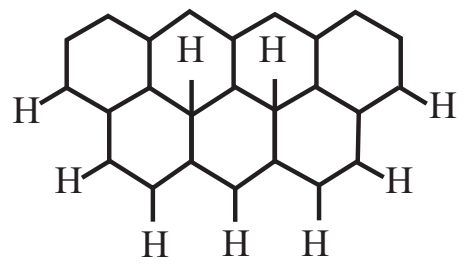

F

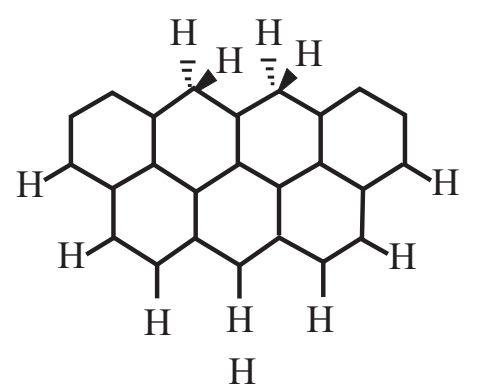

Fig. (3). (from $[34,12,10])$. Schemes of theoretical models (ab initio molecular orbital (MO) calculations) of chemisorption of atomic hydrogen on graphite (on the basal and edge planes). Chemisorption of one or two hydrogen atoms on one or two carbons in the chair-like or zigzag-like edge planes corresponds to models " $\mathrm{C}_{1}$ " and " $\mathrm{C}$ " (with the adsorption energies $\Delta H_{\text {ads("Cl"[34]) }} \approx \Delta H_{\text {ads("C" }[34])}=3.69 \mathrm{eV} / \mathrm{atom}(\mathrm{H})$ ) or "D" " and "D" (with $\Delta H_{\text {ads ("D1"[34]) }} \approx \Delta H_{\text {ads("D"[34]) }}=3.91 \mathrm{eV} /$ atom $(\mathrm{H})$ ), respectively; it can be related to thermodesorption (TD) process IV [12] with activation energy of about $3.8 \mathrm{eV} / \mathrm{atom}(\mathrm{H})$ (Fig. 4). Chemisorption of one or two hydrogen atoms on one or two carbons, every of which has 3 not occupied (by hydrogen) nearest carbons (i.e. a single-side (C-C-H) "complex" or a single-side (H-C-C-H) "complex" in the basal plane) corresponds to models " $F_{1}$ " and " $F$ " (with $\Delta H_{\text {ads }(" \mathrm{~F} 1 \text { "[34] })} \approx \Delta H_{\text {ads ("F"[34]) }}=2.01 \mathrm{eV} /$ atom $(\mathrm{H})$ ), respectively; it can be related to TDprocess III [12] with activation energy of about $2.6 \mathrm{eV} /$ atom(H) (Fig. 4). Chemisorption of two hydrogen atoms on one carbon in the edge zigzag-like plane within model "H" can be related to TD-process II [12] with activation energy of about $1.2 \mathrm{eV} / \mathrm{molecule}\left(\mathrm{H}_{2}\right)(\mathrm{Fig}$. 4). TDprocess III [12] (within model " $F_{1}$ ") in multilayer graphene structures can be related to a graphane (carbohydride) situation [13, 14], and a single-side "(C-C-H) complex" can correspond to a "molecule" of the graphite-like graphane (or carbohydride) [10, 41, 42]. A maximum (carbohydride) filling of a single side of a graphene layer in multilayer carbonaceous nanomaterials by the single-side "(C-C-H) complexes" can reach the atomic ratio $\mathrm{H} / \mathrm{C} \approx 0.5$, and it can be $\mathrm{H} / \mathrm{C} \approx 0.5$ also for the opposite side filling of the graphene layer; the total atomic ratio $\mathrm{H} / \mathrm{C}$ for the graphene (carbohydride) layer can be $\sim 1$, but without the diamond-like distortion [10, 41, 42]. A similar situation (relevance to $\mathrm{H} / \mathrm{C} \approx 1$ ) has place in the diamond-like graphane (Figs. 5D, 6)) [13, 14], which is related to filling of graphene by the two-side " $(\mathrm{H}-\mathrm{C}-\mathrm{C}-\mathrm{H})$ complexes", or "graphane molecules" (Fig. 6), that provides the diamond-like graphene distortion [10, 41, 42].

$\mathrm{H}$ (graphane) $=-2.5 \pm 0.1 \mathrm{eV}[10,42]$. This quantity coincides with the similar characteristic of the process III (Table 1 in [12]) of chemisorption of hydrogen in graphite and some carbon nanostructures.
Therefore, from a thermodynamic viewpoint, process III can be related to hydrogen thermal desorption from the graphane-like [13, 14] "centers" (Fig. 3) in near-surface layers in the graphite material [15-20]. The "open" question on a possibility of the graphane-like multilayer regions, also as 
the "open" question on a possibility of intercalation of "megabar" hydrogen between graphene (graphane-like) layers in carbonaceous materials are discussed further in the next sections.

\section{ABOUT GRAPHANE-LIKE REGIONS (CENTERS) IN GRAPHITE AND SOME CARBONACEOUS NANOSTRUCTURES}

As is shown in [10, 41, 42], the process III (in Ref [12]) of the dissociative chemical absorption of hydrogen $\mathrm{H}_{2}{ }^{\text {gas }}$ in graphene layers (model " $F_{1}$ ", Fig. 3)) of the crystal lattice of isotropic graphite [43] (Fig. 4a, b), TD peak III) and in some carbon nanostructures with $s p^{2}$ hybridization, including nanostructured graphite (Fig. 4c) [44]) and graphite nanofibers (GNFs) [35, 36], can be related to the graphene/graphane problem $[13,14]$.

Chemisorptions process III, described below by the overall reaction (5), can be presented through different steps as

$1 / 2 \mathrm{H}_{2}{ }^{\text {gas }} \Leftrightarrow \mathrm{H}^{\mathrm{s}}$,

$\mathrm{H}^{\mathrm{s}} \rightarrow \mathrm{H}^{\mathrm{l}}$,

$\mathrm{H}^{\mathrm{l}}+(\mathrm{C}-\mathrm{C})^{\mathrm{ch}} \Leftrightarrow(\mathrm{C}-\mathrm{C}-\mathrm{H})^{\mathrm{abs}}$,

$1 / 2 \mathrm{H}_{2}{ }^{\text {gas }}+(\mathrm{C}-\mathrm{C})^{\mathrm{ch}} \rightarrow(\mathrm{C}-\mathrm{C}-\mathrm{H})^{\text {abs }}$,

where $\mathrm{H}^{\mathrm{s}}$ are hydrogen atoms on the surface of graphite grains or nanoregions of the material, $\mathrm{H}^{1}$ are hydrogen atoms in the graphite lattice (between graphene layers) outside the chemisorption centers, $(\mathrm{C}-\mathrm{C})^{\mathrm{ch}}$ are internal carbon centers of chemisorption for hydrogen atoms in the graphene layers corresponding to potential $\mathrm{C}-\mathrm{C}-\mathrm{H}$ (graphane-like) complexes, and $(\mathrm{C}-\mathrm{C}-\mathrm{H})^{\text {abs }}$ are the absorbed hydrogen atoms on carbon chemisorption centers in the graphene layers of the material (i.e., C-C-H graphane-like complexes (model " $\mathrm{F}_{1}$ ", Fig. 3)).

The analysis [12] shows that in the first (dissociative (2)) and third (chemical (4)) stages of the overall process III, are in many cases close to equilibrium (local equilibrium, or reversibility), and that (2) and (4) are not limiting stages. The second stage, (3), may be diffusion-limited, i.e., the stage that determines the rate of the overall process III corresponding to the TD peak III in experiments involving temperatureprogrammed desorption of hydrogen from the material (Fig. 4).

Process III [reaction (5)] is characterized [12] by the experimental value [43] of the standard enthalpy of the bulk solution, or the chemisorption of half mole of hydrogen molecules $\mathrm{H}_{2}$ gas (the initial gaseous state) in the graphite lattice of the material $\left(\Delta H_{(5) \mathrm{III}}=-19 \pm 1 \mathrm{~kJ} \mathrm{~mol}^{-1}(\mathrm{H})=-0.20 \pm\right.$ $0.01 \mathrm{eV} / \operatorname{atom}(\mathrm{H}))$ and the experimental value $([43,16-19]$ and others [12]) of the effective enthalpy of the bulkdiffusion activation of hydrogen atoms in the graphite lattice, $Q_{\mathrm{III}}=250 \pm 3 \mathrm{~kJ} \mathrm{~mol}^{-1}(\mathrm{H})=2.59 \pm 0.03 \mathrm{eV} /$ atom $(\mathrm{H})$. The graphite quantities of $\Delta H_{(5) \mathrm{III}}$ and $Q_{\mathrm{III}}$ are related and close to the aforementioned (in Section 2) graphane quantities of $\Delta H_{\mathrm{f}(\text { theor.) }}^{0}$ and $\Delta H_{\mathrm{C}-\mathrm{H} \text { (graphane) }}[10,41,42]$, respectively.

The quantity of $\Delta H_{(5) I I I}$ can be also defined as the standard energy (enthalpy) of formation of the C-C-H graphanelike complex (i.e., $\left.\Delta H_{(5) \mathrm{III}}\right)=\Delta H_{\mathrm{f}(\mathrm{C}-\mathrm{C}-\mathrm{H})}$ ) in multilayer graphene structure of graphite lattice (reaction (5)), which is related and rather close to (or even coincides with) the grap- hane quantity of $\Delta H_{\mathrm{f} \text { (theor.) }}^{0}=-0.15 \pm 0.05 \mathrm{eV} /$ atom $(\mathrm{C})$ [13, 10, 41, 42] considered in Section 2.

Taking into account the experimental data [43] and some others (review [12]), we can approximate the mass action law for the reaction (5) as

$K_{(5) \mathrm{III}}=\left(X_{\mathrm{III}} / X_{\mathrm{IIIm}}\right) /\left\{\left(P_{\mathrm{H}_{2}} / P_{\mathrm{H}_{2}}^{0}\right)^{1 / 2}\left[1-\left(X_{\mathrm{III}} / X_{\mathrm{IIIm}}\right)\right]\right\}$,

which corresponds to the Sieverts-Langmuir absorption isotherm.
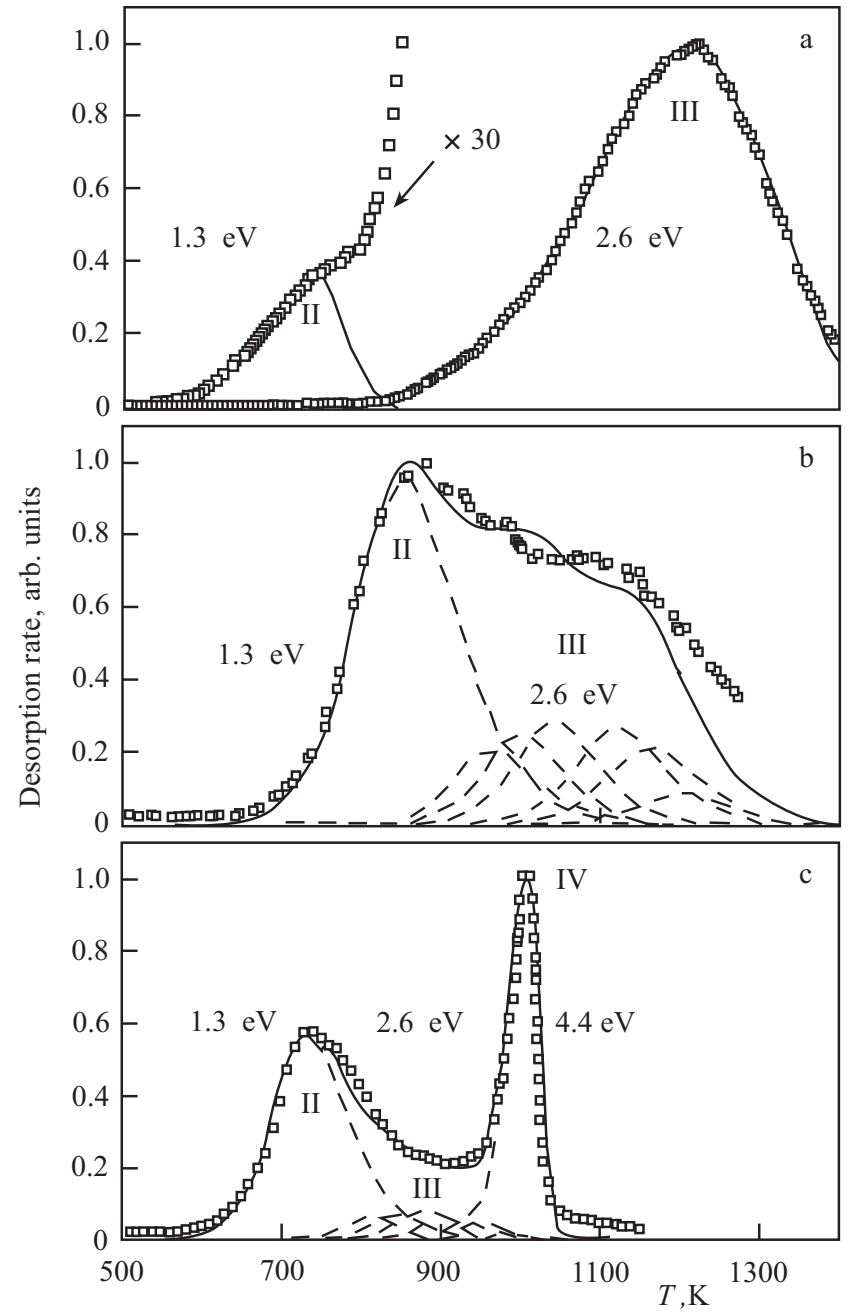

Fig. (4). Experimental curves of the temperature-programmed desorption (TD-peaks or TD-spectrum) of deuterium and the fitting curves for carbon materials: (a) ISO-88 isotropic graphite deuterium-saturated (in $\mathrm{D}_{2 \text { (gas) }}$ ) in the course of 5 hours at $973 \mathrm{~K}$ and 60 $\mathrm{kPa}$, [43]; (b) ISO-88 isotropic graphite after irradiation by $20 \mathrm{keV}$ ions of $\mathrm{D}_{2}$ with the dose $5 \cdot 10^{23} \mathrm{~m}^{-2},[43] ;$ (c) - nanostructured graphite (by mechanical synthesis with $\mathrm{D}_{2 \text { (gas) }}$ in a ball mill for 80 hours at $1 \mathrm{MPa}$ and $300 \mathrm{~K}$ ), [44]. The thermodesorption activation energies are shown: $1.3 \mathrm{eV}$ for TD-peak II, $2.6 \mathrm{eV}$ for TD-peak III, and about $4.4 \mathrm{eV}$ for TD-peak IV [12].

At small pressures $\left(K_{(5) \mathrm{III}}\left(P_{\mathrm{H}_{2}} / P_{\mathrm{H}_{2}}^{0}\right)^{1 / 2}<<1\right)$, it corresponds to the Sieverts isotherm [43]

$\mathrm{X}_{\mathrm{III}} / \mathrm{X}_{\mathrm{IIIm}}=K_{(5) \mathrm{III}}\left(P_{\mathrm{H}_{2}} / P_{\mathrm{H}_{2}}^{0}\right)^{1 / 2} /\left[1+K_{(5) \mathrm{III}}\left(P_{\mathrm{H}_{2}} / P_{\mathrm{H}_{2}}^{0}\right)^{1 / 2}\right] \approx$ $K_{(5) \text { III }}\left(P_{\mathrm{H}_{2}} / P_{\mathrm{H}_{2}}^{0}\right)^{1 / 2}$,

where the equilibrium constant for reaction (5) is described by 
$K_{(5) \text { III }}=\exp \left(\Delta \mathrm{S}_{(5) \mathrm{III}} / R\right) \exp \left(-\Delta H_{(5) \mathrm{III}} / R T\right)$,

$\Delta H_{(5) \text { III }} \approx 1 / 2 \Delta H_{\text {dis }}+\Delta H_{(4) \text { IIII }}$.

In Equations 6-8: $X_{\mathrm{III}}=\left(\mathrm{H} / \mathrm{C}^{1}\right)_{\mathrm{III}}$ is the equilibrium concentration of hydrogen atoms absorbed by the graphite lattice in the material at pressure $P_{\mathrm{H} 2}(\mathrm{~Pa})$ and temperature $T(\mathrm{~K})$, i.e., the ratio of the number of dissolved hydrogen atoms to the number of carbon atoms in the graphite lattice, which in some cases is close to the total number of carbon atoms in the material $\left(\mathrm{C}^{1} \leq \mathrm{C}\right) ; X_{\text {III } \mathrm{m}}=\left(\mathrm{H} / \mathrm{C}^{1}\right)_{\text {III } \mathrm{m}} \leq 1.0$, is the maximum (carbohydride-like) concentration $[12,45,46] ; P^{0}{ }_{\mathrm{H} 2}=1$ $\mathrm{Pa}$ is the standard pressure of hydrogen; $\Delta S_{(5) \mathrm{III}}$ is the standard entropy for reaction (5); $R$ is the gas constant; $\Delta H_{\text {dis }}=$ $448 \pm 2 \mathrm{~kJ} \mathrm{~mol}^{-1}\left(\mathrm{H}_{2}\right)$ is the experimental value [47] of the dissociation enthalpy for one mole gaseous hydrogen; $\Delta \mathrm{H}_{(2) \mathrm{III}}$ $=1 / 2 \Delta \mathrm{H}_{\mathrm{dis}}, \Delta \mathrm{H}_{(3) \text { III }} \approx 0$, and $\Delta \mathrm{H}_{(4) \text { III }}$ are the standard enthalpies for reactions (2)-(4) as applied to process III.

The first indirect experimental value $\left(\Delta H_{(4) \mathrm{III}}=-243 \pm 3\right.$ $\left.\mathrm{kJ} \mathrm{mol}^{-1}(\mathrm{H})=-2.52 \pm 0.03 \mathrm{eV} / \mathrm{atom}(\mathrm{H})\right)$ of the enthalpy of chemical C-C-H bonds formation between hydrogen atoms and the definite carbon C-C centers in graphene layers of the graphite materials is estimated via thermodynamic formula (8), by using the experimental values of $\Delta H_{(5) \text { III }}$ and $\Delta H_{\text {dis }}$.

Using the model described in [12] for the bulk diffusion of hydrogen atoms in the graphite lattice accompanied by a reversible capture on the internal (graphane-like) chemisorption C-C centers in graphene layers, we can write the effective diffusivity $\left(D_{\text {III }}\right)$ and the effective diffusion-activation enthalpy $\left(Q_{\mathrm{III}}\right)$ as

$D_{\mathrm{III}} \approx A_{\mathrm{III}} D^{1} / K_{(4) \mathrm{III}}$,

$Q_{\mathrm{III}} \approx Q^{1}-\Delta H_{(4) \mathrm{III}} \approx-\Delta H_{(4) \mathrm{III}}$,

where $A_{\text {III }} \approx$ const, $K_{(4) \text { III }}$ is the equilibrium constant for reaction (4) as applied to process III, and $D^{1}$ and $Q^{1}$ are the diffusivity and the diffusion activation enthalpy, respectively, for hydrogen atoms in a graphite lattice in absence of chemisorption capture centers (or at maximum (carbohydride) filling of these centers).

Knowing the experimental values of $Q_{\mathrm{III}}$ and $Q^{1}=7 \pm 4$ $\mathrm{kJ} \mathrm{mol}^{-1}(\mathrm{H})$ (review [12]), we can obtain the second indirect experimental value of $\Delta H_{(4) \text { III }}=-243 \pm 4 \mathrm{~kJ} \mathrm{~mol}^{-1}(\mathrm{H})$, by using thermodynamic Eqn. (10).

The value of $\Delta H_{(4) \text { III }}$ thus obtained is close to the experimental value $-255 \pm 1 \mathrm{~kJ} \mathrm{~mol}^{-1}(\mathrm{H})$ [48] of the enthalpy of C$\mathrm{C}-\mathrm{H}$ bond formation in the fullerene hydride $\mathrm{C}_{60} \mathrm{H}_{36}$ (i.e., the filling of quasigraphene spherical layer is $\mathrm{H} / \mathrm{C}=36 / 60)$ and to the theoretical values $-(220-260) \pm 20 \mathrm{~kJ} \mathrm{~mol}^{-1}(\mathrm{H})$ of the energy of C-C-H bond formation, linking hydrogen atoms to the graphene (cylindrical) surface of various single-wall nanotubes with a filling factor $\mathrm{H} / \mathrm{C}=0.5$, obtained in [45] by the density functional method. It's also consistent with the experimental data [46] on about $100 \%$ hydrogenation of carbon nanotubes through formation of stable $\mathrm{C}-\mathrm{H}$ bonds.

The obtained value of $\Delta H_{(4) \text { III }}$ is approximately half of the $\mathrm{C}-\mathrm{H}$ binding energy in the methane molecule and about half of the $\mathrm{H}-\mathrm{H}$ binding energy in the hydrogen molecule $\left(-\Delta H_{\text {dis }}\right)$ [47]. Thus, a characteristic feature of the dissociative chemisorption of hydrogen by carbon materials (process III) is the formation of approximately $50 \%$ bonds weaker than the typical chemical C-H bonds, e.g., in a methane molecule.
From Eqn (6a), it is possible to estimate that the equilibrium concentration $X_{\mathrm{III}}=\left(\mathrm{H} / \mathrm{C}^{\mathrm{l}}\right)_{\mathrm{III}}$ of the dissolved hydrogen atoms in graphite nanofibers (GNFs) and in nanostructured graphite at $300 \mathrm{~K}$ and at the hydrogen pressure in the range $1-10 \mathrm{MPa}$, is about 0.77 (about 6 wt \%). This value is defined in Ref [37] as the lower limit of the sorption capacity of adsorbent materials suitable for storing hydrogen in vehicles. The estimated value can be confirmed, as order of magnitude, by the analysis [12] of the known sorption data including $[35,36,44]$.

Unfortunately, the diffusion kinetics of chemisorbed hydrogen discharge from carbon materials at room temperature (process III) does not meet the technological requirements [37] for hydrogen-driven vehicles, mainly because of the high value of the hydrogen-diffusion activation energy $Q_{\mathrm{III}}$.

According to analysis [10, 12, 42], the obtained value of $\Delta H_{(4) \text { III }}$ can be quantitatively described (with accuracy of order of magnitude) in the framework of model " $F_{1}$ " (Fig. 3) corresponding to $s p^{3}$ rehybridization $[34,49]$, that is similar to the graphane situation [13, 14].

It's also noted [10,42] that the value of $\Delta H_{(4) \text { III }}$ coincides with the aforesaid (in Section 2$)$ value $\left(\Delta H_{\mathrm{C}-\mathrm{C}-\mathrm{H} \text { (graphane) }}=-2.5\right.$ $\pm 0.1 \mathrm{eV} / \operatorname{atom}(\mathrm{H}))$ of the bonding energy of atomic hydrogen with graphane [13,14]. And the theoretical value [13] of the standard energy (enthalpy) of formation of graphane from graphite and molecular gaseous hydrogen $\left(\Delta H_{\mathrm{f}(\text { theor. })}^{0}=\right.$ $-0.15 \pm 0.05 \mathrm{eV} /$ atom $(\mathrm{C})$ ) coincides (within errors) with the experimental value of the standard energy (enthalpy) of formation $\left(\Delta H_{(5) \text { III }}=\Delta H_{\text {f(C-C-H })}^{0}=-0.20 \pm 0.01 \mathrm{eV} /\right.$ atom $\left.(\mathrm{H})\right)$ of the C-C-H graphane-like complex (model " $\mathrm{F}_{1}$ " in Fig. 3) in the graphite lattice of multilayer graphene materials.

Meanwhile, the experimental value of $\Delta H_{(4) \text { III }}$ agrees only in order of magnitude with the theoretical value of $\Delta H_{\mathrm{ads}(\mathrm{F} 1)}=$ $-194 \mathrm{~kJ} \mathrm{~mol}^{-1}(\mathrm{H})$ [34] of the similar quantity; the relative difference is $\left.\left(\Delta H_{\mathrm{ads}(\mathrm{F} 1)^{-}}-\Delta H_{(4) \mathrm{III}}\right) / 10^{-2} \Delta H_{(4) \text { III }}\right)=-20 \%$. The calculations [34] have been done by ab initio molecular orbital (MO) method, computing the energy of atomic hydrogen chemisorption $\left(\Delta H_{\mathrm{ads}(\mathrm{F} 1)}\right)$ on graphite (on graphene plane), particularly, for model " $F_{1}$ " (Fig. 3), which can be related to the chemisorption process III [10, 12, 42].

In Fig. 3, models "E" and "F" represent hydrogen atoms adsorbed on the basal (graphene) plane sites. In model "E", two hydrogen atoms are bonded to two adjacent carbons, and in model " $F$ " they are further apart, with one carbon in between (i.e., on alternating basal sites). And the calculated value [34] of $\Delta H_{\text {ads(E1) }}$ per $\mathrm{H}$ atom for model " $\mathrm{E}_{1}$ " is $\Delta H_{\mathrm{ads}(\mathrm{E} 1)}$ $=-113 \mathrm{~kJ} \mathrm{~mol}^{-1}(\mathrm{H})$, which, obviously, is less suitable for process III (in comparison with $\Delta H_{\text {ads( }(\mathrm{Fl})}$ ).

In [50], the similar (relevance to [34]) calculations have been done by ab initio molecular orbital (MO) method, computing the energy of atomic hydrogen chemisorption $\left(\Delta H_{\text {ads }}\right)$ on graphite (on graphene plane) at very low occupancies (i.e., 1 and two hydrogen atoms within 26 carbon atoms in graphene plane sites), those are considerably lower than in [34].

In the case of one hydrogen atom adsorbed on one carbon of the basal plane carbon sites, which is related to model " $F_{1}$ " in Fig. 4, the calculated value [50] of the chemisorption energy is $\Delta H_{\mathrm{ads}(1)}=-181 \mathrm{~kJ} \mathrm{~mol}^{-1}(\mathrm{H})$, that is close to $\Delta H_{\mathrm{ads}(\mathrm{Fl})}$ 

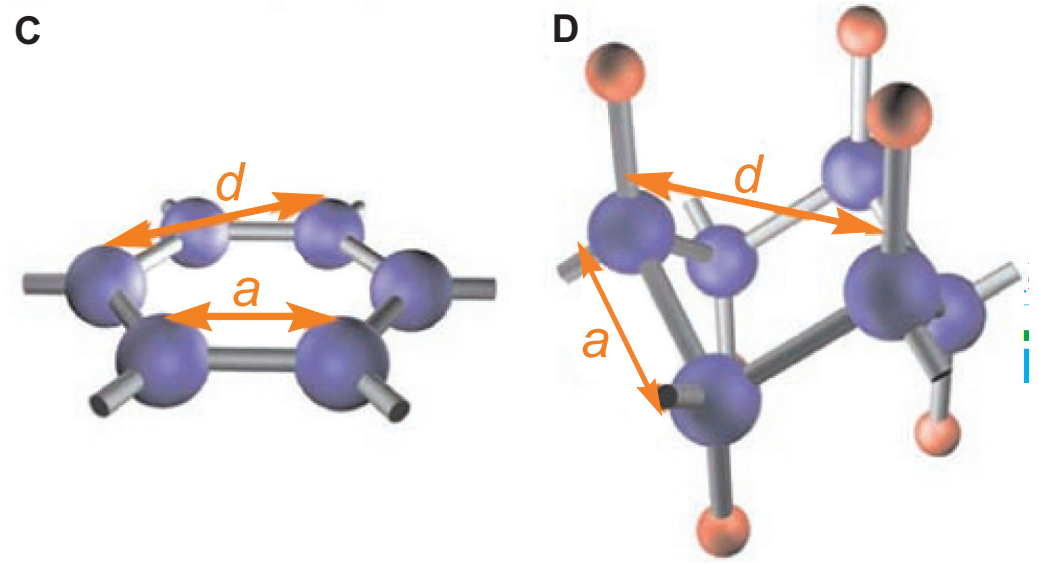

Fig. (5). Schematic representation of the graphite-like structure of graphene (C - experiment [14]), and theoretically predicted diamond-like structure of graphane in the chair-like conformation (D - theory [13]). Carbon atoms are shown as blue spheres, and hydrogen atoms are shown as red ones; $d$ is the lattice spacing (in-plane lattice parameter), $a=l_{\mathrm{C}-\mathrm{C}}$ is the C-C bond length. A two-side "H-C-C-H complex" (in D) can correspond to a "molecule" of the diamond-like graphane [13, 10, 41, 42]; an imaginary single-side "C-C-H complex" (in C) may correspond to a "molecule" of the graphite-like graphane (i.e., carbohydride) [10, 41, 42, 52].

$=-194 \mathrm{~kJ} \mathrm{~mol}^{-1}(\mathrm{H})$ [34]. In the case of two hydrogen atoms adsorbed on two alternated basal carbon sites, which corresponds to model "F" in Fig. 4, the calculated value [50] of the chemisorption energy is $\Delta H_{\mathrm{ads}(2 \text {-altern.) }}=-143 \mathrm{~kJ} \mathrm{~mol}^{-1}(\mathrm{H})$, that is also close to $\Delta H_{\text {ads(F1) }}$ [34]. In the case of two hydrogen atoms adsorbed on two adjacent basal carbon sites, which corresponds to model "E" in Fig. 4, the calculated value [50] of the chemisorption energy is $\Delta H_{\text {ads(2-adjac.) }}=-120$ $\mathrm{kJ} \mathrm{mol}^{-1}(\mathrm{H})$, that is close to $\Delta H_{\mathrm{ads}(\mathrm{E} 1)}[34]$.

In $[45,51]$, the DFT calculations have been done of the bonding characteristics of hydrogen atoms on the exterior wall of the single-walled carbon nanotubes (SWNTs), both consisting of 200 carbon atoms.

In [45], the bond energies were calculated for SWNT with $1 \mathrm{H}, 2 \mathrm{H}, 24 \%$ coverage, 50 and $100 \%$ coverage (assuming $1 \mathrm{H} / 1 \mathrm{C}$ ) of the exterior wall. The average $\mathrm{C}-\mathrm{H}$ bond formation energy for the first $\mathrm{H}$ was $-90.2 \mathrm{~kJ} \mathrm{~mol}^{-1}(\mathrm{H})$, and $170 \mathrm{~kJ} \mathrm{~mol}^{-1}(\mathrm{H})$ for the first two atoms. The average $\mathrm{C}-\mathrm{H}$ bond formation energy for $50 \%$ coverage was $239 \mathrm{~kJ} \mathrm{~mol}^{-}$ ${ }^{1}(\mathrm{H})$, decreasing to $161 \mathrm{~kJ} \mathrm{~mol}^{-1}(\mathrm{H})$ for $100 \%$ coverage of the exterior wall (a single-side filling).

In [51], the bonding of $1 \mathrm{H}$ with SWNT was studied, where the $\mathrm{H}$ atom approached the tube wall in two ways: direct approach to the top of a carbon atom (as in the case of $\Delta H_{\text {ads(1) }}$ [50]), and approach along the centerline of a hexagon. The energy minima were, respectively, $-88 \mathrm{~kJ} \mathrm{~mol}^{-1}(\mathrm{H})$ and $-234 \mathrm{~kJ} \mathrm{~mol}^{-1}(\mathrm{H})$ [51]. The latter quantity is rather close to $\Delta H_{(4) \text { III }}$, and such a situation may have place on the basal plane of graphite at low coverage.

It was also reported [51] on the $\mathrm{C}-\mathrm{C}$ bond lengths $\left(l_{\mathrm{C}-\mathrm{C}}\right)$ in the nanotube after $\mathrm{H}$ bonding. With $16 \mathrm{H}$ bonded to $64 \mathrm{C}$ on the 200-atom tube, the $l_{\mathrm{C}-\mathrm{C}}$ increased from 143 to $159 \mathrm{pm}$ [51].

A similar effect of $\mathrm{H}$ bonding on the $l_{\mathrm{C}-\mathrm{C}}$ was also seen on the basal plane of graphite [34]. In cases of models " $E$ " and "F", there are some significant increases in $l_{\mathrm{C}-\mathrm{C}}$ and $\mathrm{C}-\mathrm{H}$ bond lengths $\left(l_{\mathrm{C}-\mathrm{H}}\right)$ where hydrogen is directly involved, and decreases in Mulliken bond population, indicating weaker C$\mathrm{C}$ and $\mathrm{C}-\mathrm{H}$ bonds [34].
Particularly, in case of model " $F$ ", there are values of $l_{\mathrm{C}-\mathrm{H}}$

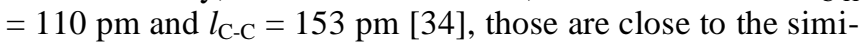
lar quantities for graphane [13, 14]. The dihedral angles (in models " $F$ " and "E") are no longer as $0^{\circ}$ or $180^{\circ}$ (as in models "A", "B", "C" and "D"), they deviate from $1^{\circ}$ to $5^{\circ}$, so that the single layer graphene sheet (Fig. 3) appears to curve away slightly (from hydrogen) [34]. It differs from the theoretical model [13] on the diamond-like structure of graphane (Figs. 5, 6), but it's close to the carbohydride-like situation $[10,41,42,52]$.

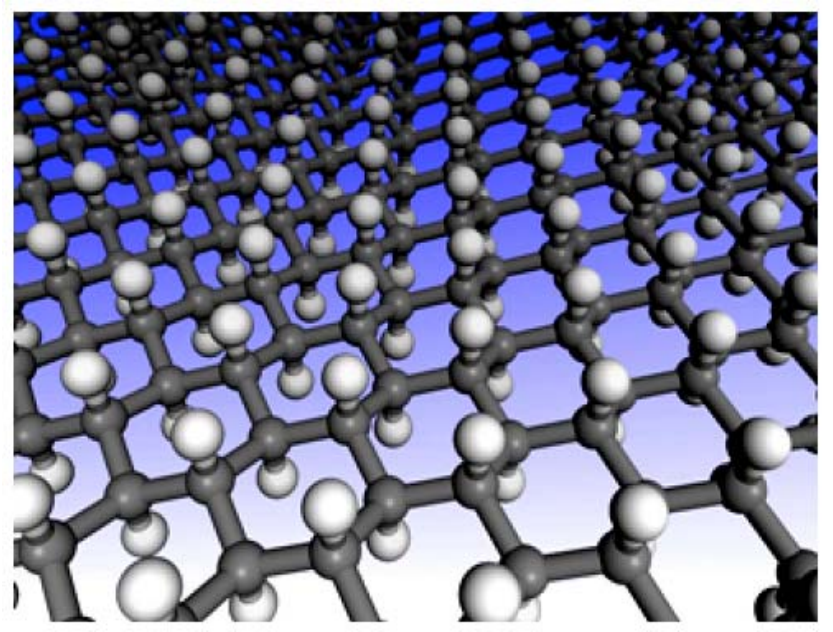

Fig. (6). Theoretically predicted [13] diamond-like structure of graphane in the chair-like conformation. The carbon atoms are shown in gray, and the hydrogen atoms in white. The figure shows the hexagonal network with carbon in the $s p^{3}$ hybridizatin. In some extent, it's related to model "F" (Fig. 3) for the case of the two-side hydrogen bonding with a graphene layer (with about $50 \%$ coverage of each side), but without the diamond-like distortion of the hexagonal network (i.e., within the graphite-like (carbohydride) structure of graphane) $[10,41,42,52]$.

Thus, the above consideration shows a possibility of formation of the graphane-like (or carbohydride-like) multilayer regions, consisting from weakly bonded (mainly, by van der 
Waals attractive interactions [13]) graphane-like sheets in some carbonaceous nanomaterials.

And is shown in the next section, the high-density ("megabar") solid molecular hydrogen can be intercalated between graphane-like layers in some carbonaceous nanomaterials (under definite conditions of their hydrogenation), which can be used for the hydrogen on-board efficient storage in fuel-cell-powered vehicles [10, 41, 42, 52].

\section{THE NECESSARY CONDITIONS FOR FORMING THE HIGH-DENSITY ( 0.7 G/CM $\left.{ }^{3}\right)$ "MEGABAR" HYDROGEN CARRIER INTERCALATED BETWEEN GRAPHANE-LIKE REGIONS IN CARBONACEOUS NANOMATERIALS}

By using data in Fig. 7, one can estimate the internal pressure of the molecular gaseous hydrogen as $P_{\mathrm{H} 2} \approx 1 \cdot 10^{8}$ $\mathrm{Pa}$ (at room temperature) corresponding to hydrogen density of $\rho \approx 0.045 \mathrm{~g} / \mathrm{cm}^{3}$. It is the density of hydrogen intercalated in near-surface blisters in HOPG at the external pressure of atomic gaseous hydrogen of $P_{\mathrm{H}} \approx 1 \mathrm{~Pa}$ and room temperature (as in [15], Figs. 1, 2). The value of $P_{\mathrm{H} 2} \approx 1 \cdot 10^{8} \mathrm{~Pa}$ is in accordance with the above estimated value of the internal pressure of molecular gaseous hydrogen of $P_{\mathrm{H} 2} \approx 3 \cdot 10^{7} \mathrm{~Pa}$ in the blisters in [15]. This accordance indicates the quantitative nature of the thermodynamic estimations using Eqn. (1).

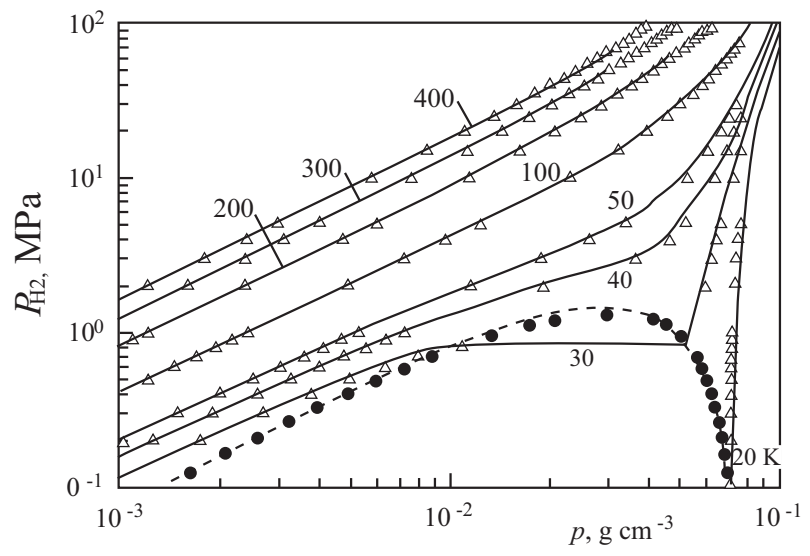

Fig. (7). (from [6], with the permition). Pressure as a function of density $(\rho)$ along the isotherms and the liquid-vapor equilibrium curve (black circles) for protium. The symbols show the experimental data, and curves plot the calculation results (isotherms are distinguished by temperature in $\mathrm{K}$ ). The isotherm of $300 \mathrm{~K}$ at $\rho=$ $0.045 \mathrm{~g} \mathrm{~cm}^{-3}$ corresponds to $P \approx 1 \cdot 10^{8} \mathrm{~Pa}$, in accordance with results $[10,11,41,42,52]$.

From data in Figs. 8 and 9 , one can estimate the external compression pressure level of $P \approx 1 \cdot 10^{11} \mathrm{~Pa}(\sim 1 \mathrm{Mbar})$ corresponding to the high desired density of $\rho \approx 0.7 \mathrm{~g} / \mathrm{cm}^{3}$ of the intercalated solid molecular hydrogen at room temperatures. Hence, by using Eq. (1), one can estimate (in the compressed gas approximation) the necessary values of $P_{\mathrm{H}} \approx 100 \mathrm{~Pa}[10$, $41,42,52]$.

Furthermore, it should be also emphasized that the carbon nanotubes and nanofibers can withstand such megabar pressure (stresses) of the compressed solid molecular hydrogen intercalated between closed graphane-like layers (nanoregions), due to their very high levels of elasticity modulus, modulus of elongation and tensile strength noted in [22-26].

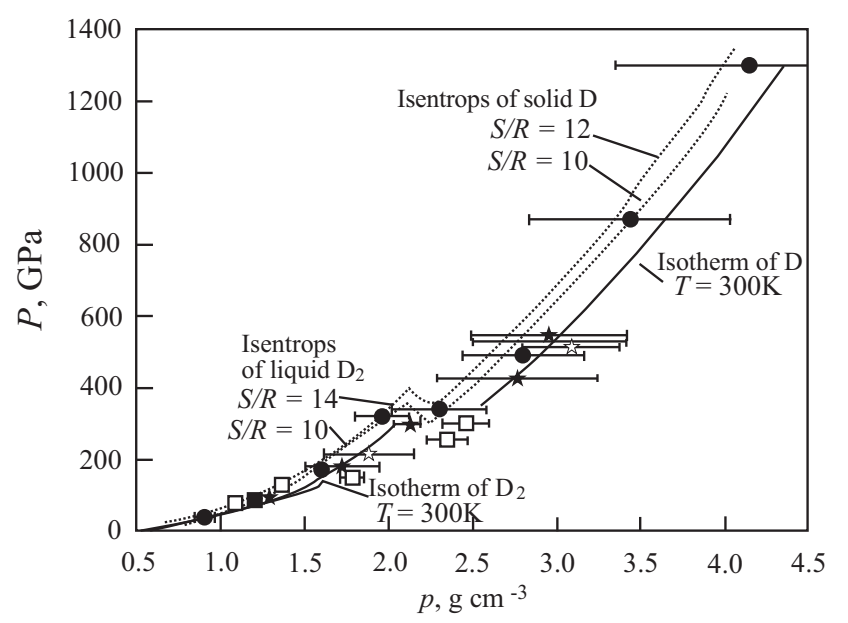

Fig. (8). (from [6], with the permition). Isentropes (at entropies $S / R$ $=10,12$ and 14, in units of the gas constant $R$ ) and isotherms (at $T$ $=300 \mathrm{~K}$ ) of molecular and atomic deuterium. The symbols show the experimental data, and curves fit calculated dependences. The density $(\rho)$ of protium was increased by a factor of two (for the scale reasons). Thickened portion of the curve is an experimental isotherm of solid form of molecular hydrogen $\left(\mathrm{H}_{2}\right)$. The quantity of $2 \rho \approx 1.4 \mathrm{~g} \mathrm{~cm}^{-3}$ of solid $\mathrm{H}_{2}$ corresponds to the external compression pressure $P \approx 1 \cdot 10^{11} \mathrm{~Pa}$, in accordance with results $[10,41,42,52]$.

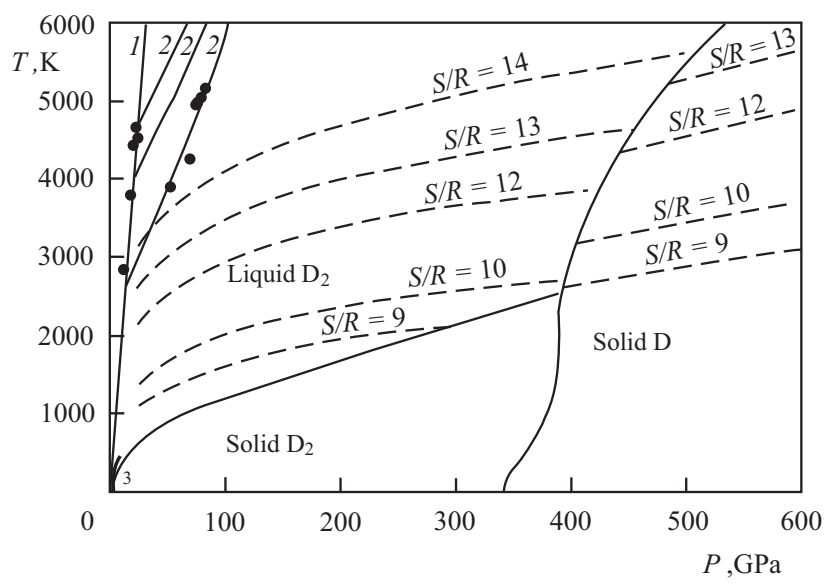

Fig. (9). (from [6], with the permition). Phase diagram, adiabats, and isentropes of deuterium calculated with the equation of state: 1 and 2 are a single and a doubled adiabat, $\bullet$ - the experimental data, 3 - melting curve, thickened portion of the curve - the experimental data. The related point $[10,41,42,52]$ with coordinates of $T \approx 300$ $\mathrm{K}$ and $P \approx 1 \cdot 10^{11} \mathrm{~Pa}$ corresponds to the solid molecular form of deuterium.

Such conditions for forming a high-density (megabar) solid molecular hydrogen carrier intercalated between graphane-like closed regions in graphite nanofibers (GNFs) can be created (in light of results [10,41, 42, 52]), by using the catalyst method of the hydrogen atomizing and closing of the edge regions of graphene (and/or graphane) layers in the material. The main result is presented in Fig. (10). 


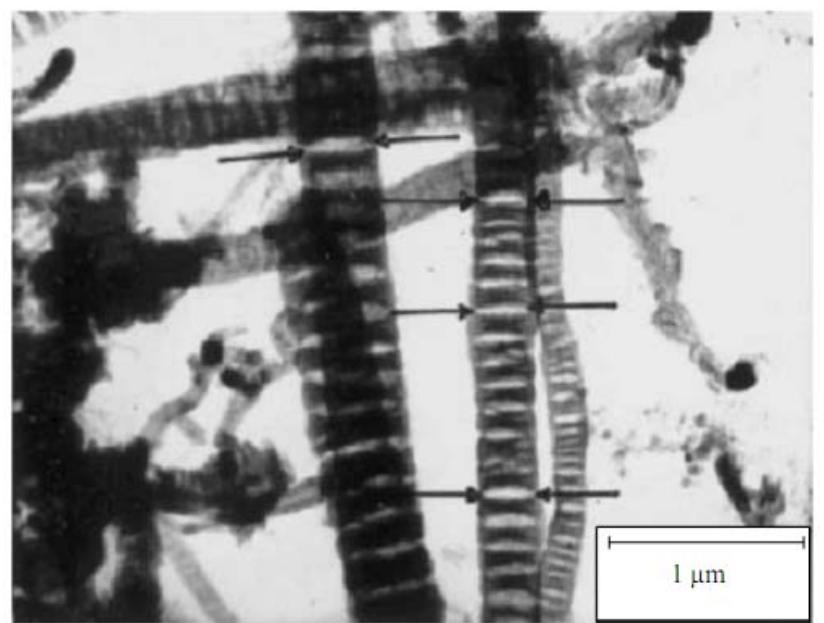

Fig. (10). (from [35, 36, 10, 41, 42, 52]). Micrographs of hydrogenated GNFs after release from them (at $\sim 300 \mathrm{~K}$, for $\sim 10 \mathrm{~min}$ ) of the intercalated solid molecular ("reversible") hydrogen ( 17 wt \% the gravimetrical hydrogen capacity), under a sharp decrease in the external pressure of gaseous molecular hydrogen (from $P_{\mathrm{H} 2} \sim 10$ $\mathrm{MPa}$ to $\left.P_{\mathrm{H} 2} \sim 1 \mathrm{MPa}\right)$. The arrows indicate some of the slit-like nanopores between multilayer graphane (carbohydride) nanoregions of the nanomaterial. The high-density solid molecular ("reversible") hydrogen of high purity was localized, mainly, within slit-like nanopores. Dehydrogenation of graphane (i.e., carbohydride) nanoregions, relevance to the covalent bonded "non-reversible" hydrogen (i.e., TD-peak III (model " $F_{1}$ " in Fig. 3, Fig. 4) occurs during thermodesorption at elevated temperatures.

The density of the intercalated hydrogen in the material (Fig. 10) can be estimated by using the relevant ordinary expressions as:

$\rho_{\mathrm{H}}=\rho_{\mathrm{C}}\left[\left(1-f_{\mathrm{vH}}\right) f_{\mathrm{mH}}\right] /\left[\left(1-f_{\mathrm{mH}}\right) f_{\mathrm{vH}}\right]$,

where $\rho_{\mathrm{C}}$ is the known GNF density $\left(\rho_{\mathrm{C}}=2.3 \mathrm{~g} / \mathrm{cm}^{3}\right), f_{\mathrm{vH}}=$ $\left[v_{\mathrm{H}} /\left(v_{\mathrm{H}}+v_{\mathrm{C}}\right)\right], v_{\mathrm{H}}$ and $v_{\mathrm{C}}$ are the volumes of the slit-like nanopores and carbon parts of GNFs, respectively, $f_{\mathrm{vH}}$ is the volume fraction of the slit-like nanopores formed in GNFs $\left(f_{\mathrm{vH}}=0,4 \pm 0,1\right.$, from Fig. 10), $f_{\mathrm{mH}}=\left[m_{\mathrm{H}} /\left(m_{\mathrm{H}}+m_{\mathrm{C}}\right)\right], m_{\mathrm{H}}$ and $m_{\mathrm{C}}$ are the masses of the intercalated (in the slit-like nanopores) solid hydrogen and the carbon part of GNFs, respectively, $f_{\mathrm{mH}}$ is the mass fraction of the intercalated solid hydrogen (in the slit-like nanopores) in GNFs $\left(f_{\mathrm{mH}}=\right.$ $0.17 \pm 0.01$ is the experimental value from [35]).

Hence, one can estimate the hydrogen density value $\left(\rho_{\mathrm{H}}=\right.$ $\left.0.7 \pm 0.2 \mathrm{~g}\left(\mathrm{H}_{2}\right) / \mathrm{cm}^{3}\left(\mathrm{H}_{2}\right)\right)$ and the hydrogen volumetric capacity $\left(\rho^{*}{ }_{\mathrm{H}}=\rho_{\mathrm{H}} f_{\mathrm{vH}}=0.28 \pm 0.08 \mathrm{~g}\left(\mathrm{H}_{2}\right) / \mathrm{cm}^{3}\right.$ (system) $)$, those in the case of the overall compression of the solid molecular hydrogen correspond to a megabar external compression pressure (Figs. 8, 9).

The external pressure can be, for instance, $P_{\mathrm{H} 2} \approx 10 \mathrm{MPa}$ (100 bar), but it should provide $P_{\mathrm{H}} \approx 100 \mathrm{~Pa}$ at the material surface (the catalyst method [10, 41, 42, 52]) with temperature about $300 \mathrm{~K}$.

There is a real possibility $[10,41,42,52]$ for quenching the high-density (megabar) hydrogen carrier and graphanelike regions in carbon-based nanomaterials for a sufficiently long time, and for establishing relevance for its detailed (stationary) studies and technological applications.
Obviously, that in our case the local internal megabar pressures in the slit-like nanopores in graphane-like regions in GNFs (Fig. 10) has occurred. This is confirmed by the observed definite swelling of the slit-like nanopores in their middle parts (Fig. 10), i.e. the lens shape of the nanopores in GNFs.

Evaluations of the necessary local stresses for such swelling of the nanopores, by using data [22-26] on the very high values of the elasticity modulus, modulus of elongation and tensile strength of the material (defect-free graphene), can produce megabar quantities. Such high local stresses (internal pressures) are formed at the expense of the energy of the hydrogen association reaction (Eqn. (1)).

Thus, in our case $[10,41,42,52]$, the external pressure of molecular hydrogen gas can be $P_{\mathrm{H} 2} \approx 10 \mathrm{MPa}(100 \mathrm{bar})$ at temperature about $300 \mathrm{~K}$, providing $P_{\mathrm{H}} \approx 100 \mathrm{~Pa}$ at the material surface (the catalyst method). It results in intercalation of solid (megabar) molecular (reversible) hydrogen of a high purity ( $\geq 17 \mathrm{wt} \% \mathrm{H}_{2}$ - the gravimetric capacity), with the hydrogen density of $\rho_{\mathrm{H}}=0.7 \pm 0.2 \mathrm{~g} / \mathrm{cm}^{3}$ and the volumetric capacity of $\rho^{*}{ }_{\mathrm{H}}=0.28 \pm 0.08 \mathrm{~g}\left(\mathrm{H}_{2}\right) / \mathrm{cm}^{3}$ (system)). These results $[10,41,42,52]$ can be applied for developing much more acceptable, safety and efficient technologies of the hydrogen on-board storage in fuel-cell-powered vehicles (with respect to the known U.S. DOE requirements [37]), compared to current technologies of composite vessels with high hydrogen pressure (about $80 \mathrm{MPa}$ ) and the space cryogenic ones.

And such a hydrogen storage nanotechnology can even exceed (in some points) the known U.S. DOE requirementstargets for 2015, with respect to the hydrogen capacities targets $\left(9.0\right.$ wt $\% \mathrm{H}_{2}, 0.081 \mathrm{~g}\left(\mathrm{H}_{2}\right) / \mathrm{cm}^{3}$ (system)), safety, reversibility and puirity.

\section{DISCUSSION ON THE GRAPHENE-GRAPHANE PROBLEM}

Publication [13] has predicted the stability of an extended two-dimensional hydrocarbon (with diamond-like structure (Figs. 5D, 6)) on the basis of first-principles total-energy calculations. This compound that has been called graphane in [13] is (according to [13]) a fully saturated hydrocarbon (Table 1) derived from a single graphene sheet with formula $\mathrm{CH}$. And as is also noted in [13]: "The graphane bonds are fully saturated and there is no opportunity for hydrogen bonding between the graphane sheets. The weak van der Walls attraction contributes negligibly..."

As is noted in [13], the relative stability of graphane may explain the possible observation of graphane-like (obviously, multilayer) structures in the case of reactive ball milling between anthracite coal and cyclohexene [54], when the delivery of atomic hydrogen does not involve splitting molecular hydrogen.

And as is also noted in [13], direct exposure of graphite to an atmosphere of gaseous molecular hydrogen $\left(\mathrm{H}_{2}\right)$ at high temperatures does not seem to be the correct path to produce graphane because hydrogen does not intercalate graphite [55] due to the higher $\mathrm{H}-\mathrm{H}$ binding energy in $\mathrm{H}_{2}$ compared to the $\mathrm{C}-\mathrm{H}$ binding energy in graphite. 
Table 1. Comparison of Experimental [47] and Theoretical [13] Values of the Standard Energy (Enthalpy) of Formation $\left(\Delta H_{\mathrm{f}}^{\mathbf{0}}\right)$ of some C-H Substances (from Graphite and/or $\mathrm{H}_{2(\text { gas })}$ at $T=298 \mathrm{~K}$ and $P_{\mathrm{H} 2}=0.1 \mathrm{M \Pi a)}[10,41,42,52]$

\begin{tabular}{|c|c|c|c|}
\hline $\begin{array}{c}\text { Substance } \\
\text { (Compound) }\end{array}$ & $\begin{array}{c}\Delta H_{\mathrm{f}(\text { experimental })}^{0}(\mathrm{eV} / \mathrm{atom}(\mathrm{C})), \\
{[47,42]}\end{array}$ & $\begin{array}{c}\Delta H_{\mathrm{f} \text { (theoretical) }}^{0}(\mathrm{eV} / \mathrm{atom}(\mathrm{C})), \\
{[\text { [13] }}\end{array}$ & $\begin{array}{l}\left(\Delta \boldsymbol{H}_{\mathrm{f}(\mathrm{th} .)}^{0}-\Delta \boldsymbol{H}_{\mathrm{f}(\mathrm{ex} .)}^{0}\right) / \\
/\left(\Delta \boldsymbol{H}_{\mathrm{f}(\mathbf{e x} .)}^{0}\right) \cdot \mathbf{1 0}^{-2}(\%)\end{array}$ \\
\hline $\begin{array}{l}\text { Methane } \\
\left(\mathrm{CH}_{4(\text { gas })}\right)\end{array}$ & -0.775 & -0.335 & -57 \\
\hline $\begin{array}{c}\text { Benzene } \\
\left(\mathrm{C}_{6} \mathrm{H}_{6 \text { (liquid) }}\right)\end{array}$ & +0.085 & -0.075 & -188 \\
\hline Cyclohexene $\left(\mathrm{C}_{6} \mathrm{H}_{10(\text { (liquid) }}\right)$ & -0.127 & -0.165 & +30 \\
\hline Cyclohexane $\left(\mathrm{C}_{6} \mathrm{H}_{12 \text { (liquid) }}\right)$ & -0.270 & -0.240 & -11 \\
\hline $\begin{array}{l}\text { Polyethylene } \\
\left(-\mathrm{CH}_{2}-\mathrm{CH}_{2}-\right)_{\mathrm{n}(\text { solid })}\end{array}$ & & -0.240 & \\
\hline $\begin{array}{l}\text { Atomic carbon } \\
\qquad\left(\mathrm{C}_{(\mathrm{gas})}\right)\end{array}$ & 7.35 & 9.55 & +30 \\
\hline $\begin{array}{l}\text { Atomic hydrogen } \\
\qquad\left(\mathrm{H}_{\text {(gas) }}\right)\end{array}$ & 2.26 & 3.27 & +45 \\
\hline $\begin{array}{l}\text { Graphane (diamond-like struct.) } \\
\qquad\left(\mathrm{CH}_{\text {(solid) }}\right)\end{array}$ & & $-0.15 \pm 0.05$ & $\leftarrow< \pm \underline{\underline{35}}>$ \\
\hline
\end{tabular}

As is noted in [14]: "Although graphite is known as one of the most chemically inert materials, we have found that graphene, a single atomic plane of graphite, can react with atomic hydrogen, which transforms this highly conductive semimetal (single-layer graphene) into an insulator (graphane)."

But hydrogen chemisorption by graphite and related carbon nanostructures (Figs. 3, 4) is not taken into account in $[13,14]$, and particularly, process III [12], for which the C-H binding energy in graphite is higher than the $\mathrm{H}-\mathrm{H}$ binding energy in $\mathrm{H}_{2}$. Obviously, graphite and related carbon nanostructures are chemically active (almost as much as graphene is) in relation to hydrogen. Hence, multilayer graphane-like (carbohydride-like) material can be derived from multilayer graphene sheets under definite hydrogenation conditions, for instance, from graphite nanofibers (Fig. 10) [10, 41, 42, 52].

A possibility of formation of the multilayer graphane-like regions and/or nanomaterials (from multilayer graphene materials, under definite hydrogenation conditions, is proved (shown) by the following facts.

Firstly, the theoretical value [13] of the standard energy (enthalpy) of formation of graphane from graphite and molecular gaseous hydrogen $\left(\Delta H_{\mathrm{f}(\text { theor. })}^{0}=-0.15 \pm 0.05\right.$ $\mathrm{eV} /$ atom(C)), Tables 1 and 2) coincides (within errors) with the experimental value of the standard energy (enthalpy) of formation $\left(\Delta H_{(5) \text { III }}=\Delta H_{\mathrm{f}(\mathrm{C}-\mathrm{H})}^{0}=-0.20 \pm 0.01 \mathrm{eV} /\right.$ atom $\left.(\mathrm{H})\right)$ of the $\mathrm{C}-\mathrm{C}-\mathrm{H}$ graphane-like complex (model " $\mathrm{F}_{1}$ " in Fig. 3) in the graphite lattice of multilayer graphene materials (Table 2).

Secondly, as is noted in Section 2 (using data [13, 47]), the bonding energy of atomic hydrogen with graphane $\left(\Delta H_{\mathrm{C}}\right.$ $\mathrm{H}($ graphane) $=-2.5 \pm 0.1 \mathrm{eV}$ ) (Table 2) essentially coincides with the indirect experimental value $\left(\Delta H_{(4) \text { III }}=\Delta H_{\mathrm{C}-\mathrm{H} \text { (graphite) }}=\right.$ -
$2.52 \pm 0.03 \mathrm{eV} /$ atom $(\mathrm{H})$ ) of bonding energy of atomic hydrogen with the graphite lattice (the $\mathrm{C}-\mathrm{C}-\mathrm{H}$ graphane-like complex (model " $F_{1}$ " in Fig. 3)) for the chemisorption process III [12] in multilayer graphene materials (Table 2).

Thirdly, thermodynamic analysis $[10,41,42,52]$ of the related data (including [13, 14]) shows a possibility of formation of both graphane (carbohydride) and multilayer graphane (multilayer carbohydride) with graphite-like structure (Table 2).

Fourtly, a comparision of the $\Delta H_{\mathrm{C}-\mathrm{C}}$ quantities of carbon materials (Table 2) shows that an experimental graphane (carbohydride) can possess of about the same strength properties as an experimental graphene possesses, in contrary to the theoretical diamond-like graphane.

It is consistent with experimental data [14] about formation of a single-side graphane in the case of a single-side graphene on a substrate $\left(\mathrm{SiO}_{2}\right)$, where only one side of graphene is accessible for atomic hydrogen. As is noted in [14], the single-side graphene hydrogenation is in contradiction with theory [13] on the diamond-like graphane structure (Figs. 5D, 6) allowing only two-side graphene hydrogenation. But it seems possible for the graphite-like graphane (carbohydride) structure (Table 2), with occurring of some ripples for the graphene hydrogenation noted in [14].

In [14], the same hydrogenation procedures ( 2 hours exposure in cold hydrogen plasma) both for single-layer and bilayer (on a $\mathrm{SiO}_{2}$ substrate) graphene samples have been applied. Bilayer samples exhibited significantly lower affinity for hydrogen, as compared to single-layer graphene samples. As has been proposed in [14], this observation agrees with the theory [13] that hydrogen cannot be adsorbed on one side of a flat graphene, and with their conclusions that hydrogen adsorption for single-side graphene on a substrate 
Table 2. Comparison of Thermodynamic and Crystal-Chemical Characteristics of Graphite (Multilayer Graphene), Graphene, Diamond, Graphane and Multilayer Graphane (Carbohydride) $[10,41,42,52]$

\begin{tabular}{|c|c|c|c|c|c|c|}
\hline $\begin{array}{l}\text { Carbon } \\
\text { material }\end{array}$ & $\begin{array}{c}\Delta H_{\mathrm{f}}^{0} \\
(\mathrm{eV} / \text { atom })\end{array}$ & $\begin{array}{c}-\Delta H_{\mathrm{C}-\mathrm{C}} \\
(\mathrm{eV})\end{array}$ & $\begin{array}{c}-\Delta H_{\mathrm{C}-\mathrm{H}} \\
(\mathrm{eV})\end{array}$ & $\begin{array}{l}l_{\mathrm{C}-\mathrm{C}} \\
(\AA)\end{array}$ & $\begin{array}{l}l_{\mathrm{C}-\mathrm{H}} \\
(\AA)\end{array}$ & $\begin{array}{c}d \\
(\AA)\end{array}$ \\
\hline $\begin{array}{c}\text { Graphite } \\
\text { (multigraphene) }\end{array}$ & $\begin{array}{c}0.0 \\
{[47]}\end{array}$ & $\begin{array}{c}4.94 \pm 0.03 \\
{[12,47]}\end{array}$ & & $\begin{array}{c}1.42 \\
{[14,13]}\end{array}$ & & $\begin{array}{c}2.46 \\
{[14,13]}\end{array}$ \\
\hline Graphene & $\begin{array}{c}\leq 0.1 \\
{[13,47]}\end{array}$ & & & $\begin{array}{c}1.42 \\
{[14,13]}\end{array}$ & & $\begin{array}{c}\langle 2.46\rangle \\
\pm 0.02[14]\end{array}$ \\
\hline Diamond & $0.020 \pm 0.001[47]$ & $\begin{array}{c}3.69 \pm 0.01 \\
{[12,47]}\end{array}$ & & $\begin{array}{c}1.53 \\
{[14,13]}\end{array}$ & & \\
\hline $\begin{array}{l}\text { Graphane [13] (dia- } \\
\text { mond-like structure) }\end{array}$ & $\begin{array}{c}-0.15 \\
\pm 0.05 \\
{[13,42,52]}\end{array}$ & $\begin{array}{c}2.7 \pm 1.0 \\
{[13,42,47]}\end{array}$ & $\begin{array}{c}2.5 \pm 0.1 \\
{[13,42,47]}\end{array}$ & $\begin{array}{l}1.52(3) \\
{[13,53]}\end{array}$ & $\begin{array}{l}1.11 \\
{[13]}\end{array}$ & $\begin{array}{c}2.43 \\
{[13,53]}\end{array}$ \\
\hline $\begin{array}{l}\text { Graphane [14] (ex- } \\
\text { periment) }\end{array}$ & & & & & & $\begin{array}{c}\langle 2.42\rangle \\
\pm 0.09[14]\end{array}$ \\
\hline $\begin{array}{l}\text { Multigraphane (ex- } \\
\text { periment) }\end{array}$ & $\begin{array}{l}-0.20 \pm 0.01 \\
{[10,42,52]}\end{array}$ & $\begin{array}{l}4.91 \pm 0.03 \\
{[10,42,52]}\end{array}$ & $\begin{array}{l}2.52 \pm 0.03 \\
{[10,42,52]}\end{array}$ & & & \\
\hline $\begin{array}{l}\text { Graphane (graphite- } \\
\text { like structure) }\end{array}$ & $\begin{array}{c}-0.2 \\
{[10,41,42,52]}\end{array}$ & $\begin{array}{c}4.9 \\
{[10,41,42,52]}\end{array}$ & $\begin{array}{c}2.5 \\
{[10,41,42,52]}\end{array}$ & & & \\
\hline
\end{tabular}

is facilitated by ripples. And as has been also proposed in [14], higher rigidity of bilayers suppresses their rippling, thus reducing the probability of hydrogen adsorption.

But the bilayer graphene data [14] may be also related to data [15] (Section 2) on the graphene blister formation in surface bilayers in HOPG, and also with data [12] (Section 3 ) on a sluggish kinetics of the hydrogen absorption in multilayer graphene (process III, Figs. 3, 4). It can result in decreasing the affinity for hydrogen in the case of bilayer samples [14].

As is noted in [14], the diamond-like graphane [13] is an "until-now-theoretical material", and the experimentally produced graphane, particularly, relevance to anomalous values of the lattice spacing $d$ (Table 2), may have a more complex hydrogen bonding than one suggested by theory [13].

The above consideration of the graphene/graphane problem shows the following points:

1. It is expedient to consider an experimental graphane $(\mathrm{CH})$ not as a hydrocarbon, but as a carbohydride (the graphene hydride).

2. Graphane may have not only the diamond-like structure (theory), but the graphite-like one (experiment), as well.

3. An experimental graphane (carbohydride) can possess of about the same strength properties as an experimental graphene possesses, in contrary to the theoretical diamond-like graphane.

4. The graphane-like (carbohydride-like) nanoregions (nanostructures) can have place in some carbonaceous multilayer nanomaterials (graphite nanofibers and others).

\section{SUMMARY}

This research obtained the following results.

First, a thermodynamic theory (description) of the process of high-density hydrogen intercalation into (between) near-surface graphene layers of highly oriented pyrolytic graphite was developed and confirmed by comparing with experimental and theoretical data. It includes kinetic (diffusion) aspects, taking into account several processes of hydrogen chemisorption, and in particular, possible formation of graphane-like (carbohydride-like) complexes.

Second, a thermodynamic theory (description) of the process of high-density solid molecular hydrogen intercalation into (between) closed graphane-like layers (nanoregions) of novel carbonaceous nanomaterials (graphite nanofibers) was also developed and confirmed by comparing with experimental and theoretical data. The necessary level of atomic hydrogen external pressures $\left(P_{\mathrm{H}} \approx 100 \mathrm{~Pa}\right)$, which is necessary to intercalate solid molecular hydrogen of density $\rho \approx 0.7 \mathrm{~g}\left(\mathrm{H}_{2}\right) / \mathrm{cm}^{3}\left(\mathrm{H}_{2}\right)$ in carbonaceous nanostructures (at room temperatures), was estimated and confirmed by comparing with experimental and theoretical data. As is shown, it corresponds to formation of a megabar local internal pressure (stresses) in closed graphane-like nanoregions at the cost of energy of the local association of hydrogen atoms. Particularly, it is confirmed by local swelling of the nanomaterial.

Third, there are serious reasons to propose that a process of dissociative chemisorption of hydrogen between graphene layers in some carbonaceous nanostructures can be related to formation of graphane-like (carbohydride-like) complexes and/or nanoregions. 
Fourth, the necessary conditions for formation of a highdensity solid molecular (reversible) hydrogen carrier of a high purity intercalated between graphane-like layers (nanoregions) in carbonaceous nanomaterials $\left(\geq 15\right.$ wt $\% \mathrm{H}_{2}$ - the gravimetric hydrogen density) were defined.

Fifth, by using gravimetric and electron microscopy data, the density value $\left(\rho_{\mathrm{H}}=0.7 \pm 0.2 \mathrm{~g}\left(\mathrm{H}_{2}\right) / \mathrm{cm}^{3}\left(\mathrm{H}_{2}\right)\right)$ and the volumetric capacity value $\left(\rho_{\mathrm{H}}=0.28 \pm 0.04\right.$ $\mathrm{g}\left(\mathrm{H}_{2}\right) / \mathrm{cm}^{3}$ (system)) of the intercalated solid molecular (reversible) hydrogen in graphane-like nanofibers were defined. As is shown, in this case the external pressure of molecular hydrogen gas can be $P_{\mathrm{H} 2} \approx 10 \mathrm{MPa}(100 \mathrm{bar})$ at temperature about $300 \mathrm{~K}$, providing $P_{\mathrm{H}} \approx 100 \mathrm{~Pa}$ at the nanomaterial surface (the catalyst method), and resulting in intercalation of reversible megabar hydrogen carrier.

These results can be applied for developing much more acceptable, safety and efficient technologies of the hydrogen on-board storage in fuel-cell-powered vehicles, compared to current technologies of composite vessels with high hydrogen pressure (about $80 \mathrm{MPa}$ ) and the space cryogenic ones.

And such a hydrogen storage nanotechnology can even exceed (in some points) the known U.S. DOE requirementstargets for 2015, with respect to the hydrogen capacities targets $\left(9.0\right.$ wt $\% \mathrm{H}_{2}, 0.081 \mathrm{~g}\left(\mathrm{H}_{2}\right) / \mathrm{cm}^{3}$ (system)), safety, reversibility and puirity. It could be also beneficial for other industries, for instance, those working on hydrogen generation from water splitting, by using either nuclear or tidal energy. And it may be of great benefit to an overall solution to the problem of hydrogen storage and distribution.

\section{REFERENCES}

[1] Badiei, S.; Holmlid, L. Atomic hydrogen in condensed form produced by a catalytic process: A future energy-rich fuel? Energy $\mathrm{Fu}$ els, 2005, 19, 2235-2239.

[2] Silvera, I.F.; Cole, J.W. Metallic hydrogen: The most powerful rocket fuel yet exists. J. Phys. Conf. Ser., 2010, 215, Article no. 012194.

[3] Badiei, S.; Andersson, P.U.; Holmlid, L. Fusion reactions in highdensity hydrogen: A fast route to small-scale fusion? Int. J. Hydrogen Energy, 2009, 34, 487-495.

[4] Badiei, S.; Holmlid, L. Condensed atomic hydrogen as a possible target in intertial confinement fusion (ICF). Fusion Eng. Des., 2008, 27, 296-300.

[5] Manykin, E.A.; Ozhovan, M.I.; Poluéktov, P.P. Transition of an excited gas to a metallic state. Tech. Phys. Lett., 1980, 6, 95-99.

[6] Trunin, R.F.; Urlin, V.D.; Medvedev, A.B. Dynamic compression of hydrogen isotopes at megabar pressures. Phys. Usp., 2010, 53(6), 605-622.

[7] Borisov, G.V.; Bykov, A.I.; Il'kaev, R.I.; Seemir, V.D.; Simakov, G.V.; Trunin, R.F.; Urlin, V.D; Shuikin, A.N.; Nellis, W.J. Shok compression of liquid deuterium up to 109 GPa. Phys. Rev. B: Condens. Matter. Mater. Phys., 2005, 71(9), 1-4.

[8] Vereshchagin, L.F.; Yakovlev, E.N.; Timofeev, Yu.A. Possibility of transition of hydrogen into the metallic state. J. Exp. Theor. Phys. Lett., 1975, 21(3), 85-88.

[9] Mao, H.-K.; Hemley, R.J. Ultrahigh-pressure transitions in solid hydrogen. Rev. Modern Phys., 1994, 66 (2), 671-692.

[10] Nechaev, Yu.S. High-density hydrogen within carbonaceous nanostructures: The very powerful vehicle and rocket fuel. Int. Sci. J. Astronautics, 2010, 1(1), 52-63.

[11] Nechaev, Y.uS.; Alexeeva, O.K.; Oechsner, A. On the hydrogen multilayer intercalation in carbonaceous nanostructures: Relevance for development of super-adsorbents for fuel-cell-powered vehicles. J. Nanosci. Nanotechnol., 2009, 9(6), 3949-3958.

[12] Nechaev, Yu.S. Carbon nanomaterials, relevance to solving the hydrogen storage problem. J. Nano. Res., 2010, 12, 1-44.
[13] Sofo, J.O.; Chaudhari, A.S.; Barber, G.D. Graphane: a twodimensional hydrocarbon. Phys. Rev. B., 2007, 75, no.153401:153401-4.

[14] Elias, D.C.; Nair, R.R.; Mohiuddin, T.M.; Morozov, S.V.; Blake, P.; Halsall, M.P.; Ferrari, A.S.; Boukhvalov, D.W.; Katsnelson, M.I.; Geim, A.K.; Novoselov, K.S. Control of graphene's properties by reversible hydrogenation: Evidence for graphane. Science, 2009, 323(5914), 610-613.

[15] Waqar, Z. Hydrogen accumulation in graphite and etching of graphite on hydrogen desorption. J. Mater. Sci., 2007, 42, 11691176.

[16] Denisov, E.A.; Kompaniets, T.N.; Makarenko, I.V.; Vakar, Z.; Titkov, A.N. Hydrogen thermosorption from pyrolytic graphite exposed to atomic hydrogen. Materialovedenie (Materials science), 2003, 2, 45-49.

[17] Denisov, E.A.; Kompaniets, T.N. Kinetics of hydrogen release from graphite after hydrogen atom sorption. Phys. Scr. T., 2001, 94, 128-131.

[18] Denisov, E.A.; Kompaniets, T.N. Interaction of graphite with atomic hydrogen. Tech. Phys., 2001, 46(2), 240-244.

[19] Waqar, Z.; Denisov, E.A.; Kompaniets, T.N.; Makarenko, I.V.; Titkov, A.N. Modification of graphite surface in the course of atomic hydrogen sorption STM and AFM study. Phys. Scr. T., 2001, 94, 132-136.

[20] Thomas, C.; Layet, J.-M.; Angot, T. Atomic hydrogen interaction with HOPG surface. In Extended Abstracts, Carbon 2006, The British Carbon Group (2006). The Robert Gordon University.

[21] San, M. C.; Somerday, B.P.; Robinson, S.L. Permeability, solubility and diffusivity of hydrogen isotopes in stainless steels at high gas pressure. Int. J. Hydrogen Energy, 2007, 32, 100-116.

[22] Wong, E.W.; Sheehan, P.E.; Lieber, C.M. Nanobeam mechanics: Elastisity, strength, and toughness of nanorods and nanotubes. Science, 1997, 277(5334), 1971-1975.

[23] Kim, H.; Kaufman, M.J.; Sigmund, W.M.; Jacques, D.; Andrews, R. Observation and formation mechanism of stable face-centeredcubic Fe nanorods in carbon nanotubes. J. Mater. Res. 2003, 18(5), 1104-1108.

[24] Galanov, B.A.; Galanov, S.B.; Gogotsi, Y. Stress-strain state of multiwall carbon nanotube under internal pressure. J. Nanopart. Res., 2002, 4(3), 207-214.

[25] Banhart, F.; Ajayan, P.M. Carbon onions as nanoscopic pressure cells for diamond formation. Nature, 1996, 382(6590), 433-435.

[26] Lee, C.; Wei, X.; Kysar, J.W.; Hone, J. Measurement of the elastic properties and intrinsic strength of monolayer graphene. Science, 2008, 321(5887), 385-388.

[27] Han, S.S.; Kang, J.K.; Lee, H.M. Liquefaction of $\mathrm{H}_{2}$ molecules upon exterior surfaces of carbon nanotube bundles. Appl. Phys. Lett., 2005, 86, 203108, 1-9.

[28] Ye, Y.; Ahn, C.C.; Witham, C.; Fultz, B.; Liu, J.; Rinzler, A.G.; Colbert, D.; Smith, K.A.; Smalley, R.E. Hydrogen adsorption and cohesive energy of single-walled carbon nanotubes. Appl. Phys. Lett., 1999, 74, 2307-2309.

[29] Allouche, A.; Ferro, Y.; Angot, T.; Thomas, C.; Layet J.-M. Hydrogen adsorption on graphite (0001) surface: A combined spectroscopy-density-functional-theory study. J. Chem. Phys., 2005, 123(12), 124701,1-6.

[30] Ma, Y.; Xia, Y.; Zhao, M.; Ying, M. Structures of hydrogen molecules in single-walled carbon nanotubes. Chem. Phys. Lett., 2002 , 357(1-2), 97-102.

[31] Xia, Y.; Zhao, M.; Ma, Y.; Ying, M.; Liu, X.; Liu, P.; Mei, L. Tensile strength of single-walled carbon nanotubes with defects under hydrostatic pressure. Phys. Rev. B: Condens. Matter Mater. Phys., 2002, 65(15), 155415, 1554151-7.

[32] Xia, Y.; Zhao, M.; Ma, Y.; Liu, X.; Ying, M.; Mei, L. Condensation and phase transitions of hydrogen molecules confined in single-walled carbon nanotubes. Phys. Rev. B: Condens. Matter Mater. Phys., 2003, 67(11), 115117, 1151171-5.

[33] Ma, Y.C.; Xia, Y.; Zhao, M.; Ying, M. Hydrogen storage capacity in single-walled carbon nanotubes. Phys. Rev. B: Condens. Matter Mater. Phys., 2002, 65(15), 155430, 1554301-6.

[34] Yang, F.H.; Yang, R.T. Ab initio molecular orbital study of adsorption of atomic hydrogen on graphite: Insight into hydrogen storage in carbon nanotubes. Carbon, 2002, 40, 437-444.

[35] Gupta, B.K.; Tiwari, R.S.; Srivastava, O.N. Studies on synthesis and hydrogenation behavior of graphitic nanofibers prepared 
through palladium catalyst assisted thermal cracking of acetylene. J. Alloys Compd., 2004, 381, 301-308.

[36] Park, C.; Anderson, P.E.; Chambers, A.; Tan, C.D.; Hidalgo, R.; Rodriguez, N.M. Further studies of the interaction of hydrogen with graphite nanofibers. J. Phys. Chem. B, 1999, 103, 1057210581.

[37] Satyapal, S.; Petrovic, J.; Read, C.; Thomas, G.; Ordaz, G. The U.S. Department of Energy's national hydrogen storage project: progress towards meeting hydrogen-powered vehicle requirements. Catal. Today, 2007, 120, 246-257.

[38] Lee, S.M.; An, K.H.; Lee, Y.H.; Seifert, G.; Frauenheim, T. A hydrogen storage mechanism in single- walled carbon nanotubes. $J$. Am. Chem. Soc., 2001, 123(21), 5059-5063.

[39] Nikitin, A.; Ogasawara, H.; Mann, D.; Denecke, R; Zhang, Z.; Dai, H.; Nillson, A. Hydrogenation of single-walled carbon nanotubes. Phys. Rev. Lett., 2005, 95(22), 225507, 1-4.

[40] Lupu, D.; Biris, A.R.; Misan, I.; Jianu, A.; Holzhüter, G.; Burkel, E. Hydrogen uptake by carbon nanofibers catalyzed by palladium. Int. J. Hydrogen Energy, 2004, 29, 97-102.

[41] Nechaev, Yu.S. Method of producing the high-density hydrogen carrier. Russian potential patents № 2010134792, № 2010153171, 2011.

[42] Nechaev, Yu.S. Thermodynamic and technology aspects of the graphene/graphane problem, relevance to the condensed hydrogen intercalation in multigraphane. In: International Hydrogen Research Showcase 2011, UK, University of Birmingham, UK, April 13-15, 2011; the UK-SHEC website: http://www.ukshec.org.uk/uk-shec/showcase/ShowcasePresentations.html

[43] Atsumi, H.; Tauchi K. Hydrogen absorption and transport in graphite materials. J. Alloys Compounds, 2003, 356-357, 705-709.

[44] Orimo, S.; Züttel, A.; Schlapbach, L.; Majer, J.; Fukunaga, T.; Fujii, H. Hydrogen interaction with carbon nanostructures: current and future prospects. J. Alloys Compounds, 2003, 356-357, 716719 .
[45] Bauschlicher, C. W., Jr.; So, C. R. High coverages of hydrogen on $(10,0),(9,0)$ and $(5,5)$ carbon nanotubes. Nano. Lett., 2002, 2,337 341 .

[46] Nikitin, A.,; Li, X.; Zhang, Z.; Ogasawara, H.; Dai, H.; Nilsson, A. Hydrogen storage in carbon nanotubes through the formation of stable C-H bonds. Nano Lett., 2008, 8(1), 162-167.

[47] Karapet'yants, M. K.; Karapet'yants M.L. Osnovnye Termodinamicheskie Konstanty Neorganicheskikh $i$ Organicheskikh Veshchestv (Fundamental Thermodynamic Constants of Inorganic and Organic Substances); Khimiya; Moscow, 1968.

[48] Pimenova, S.M.; Melkhanova, S.V.; Kolesov, V.P.; Lobach, A.S. The enthalpy of formation and $\mathrm{C}-\mathrm{H}$ bond enthalpy of hydrofullerence $\mathrm{C}_{6} \mathrm{OH}_{36}$. J. Phys. Chem. B, 2002, 106, 2127-2130.

[49] Volpe, M.; Cleri, F. Chemisorption of atomic hydrogen in graphite and carbon nanotubes. Surface Sci., 2003, 544, 24-34.

[50] Yang, F.H.; Lachawiec, A.J., Jr.; Yang, R.T. Adsorption of spillover hydrogen atoms on single-wall carbon nanotubes. J. Phys. Chem. B, 2006, 110, 6236-6244.

[51] Froundakis, G.E. Hydrogen interaction with single-walled carbon nanotubes: A combined quantum-mechanics/molecular mechanics study. Nano Lett., 2001, 1(4), 179-182.

[52] Nechaev, Y.S. On the high-density "megabar" hydrogen in graphane-like carbonaceous multilayer nanostructures. Int. Sc. J. Alternative Energy Ecology, 2010, 10, 51-59.

[53] Boukhvalov, D.W.; Katsnelson, M.I.; Lichtenstein, A.I. Hydrogen on graphene: Electronic structure, total energy, structural distortions and magnetism from first-principles calculations. Phys. Rev. B - Condens. Matter. Mater. Phys., 2008, 77(3), no 035427.

[54] Lueking, A.D.; Gutierrez, H.R.; Fonseca, D.A.; Narayanan, D.L.; Essendelft, D.V.; Jain, P.; Clifford, C.E.B. Combined hydrogen production and storage with subsequent carbon crystallization. $J$. Am. Chem. Soc., 2006, 128, 7758-7763.

[55] Dresselhaus, M.S.; Dresselhaus, G. Interaction compounds of graphite. Adv. Phys., 1981, 30(2), 139-326.

(C) Yury S. Nechaev; Licensee Bentham Open.

This is an open access article licensed under the terms of the Creative Commons Attribution Non-Commercial License (http://creativecommons.org/licenses/by-nc/3.0/) which permits unrestricted, non-commercial use, distribution and reproduction in any medium, provided the work is properly cited. 